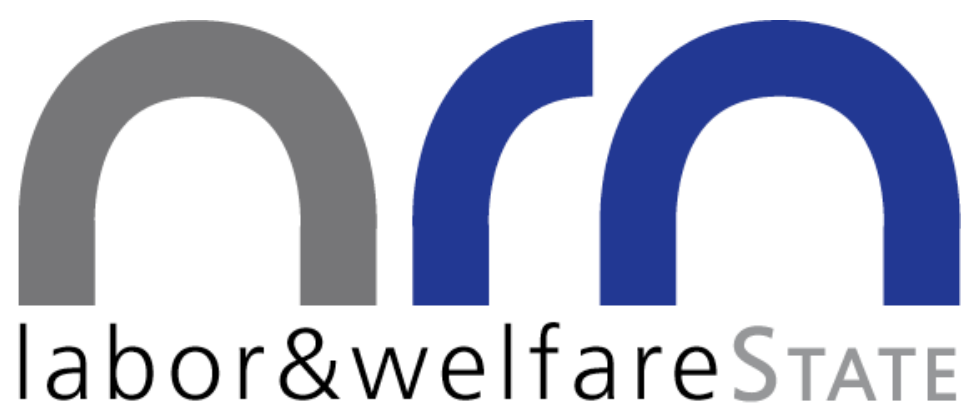

The Effect of Health on Earnings: Quasi-Experimental Evidence from Commuting Accidents

by

\author{
Martin HALLA \\ Martina ZWEIMÜLLER
}

Working Paper No. 1103

June 2011

Supported by the

Austrian Science Funds

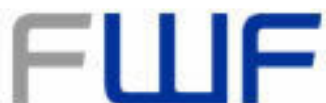

The Austrian Center for Labor Economics and the Analysis of the Welfare State

JKU Linz

Department of Economics

Altenberger Strasse 69

4040 Linz, Austria

www.labornrn.at

Corresponding author: martin.halla@jku.at phone +43 (0)70 $2468-8706,-28706$ (fax) 


\title{
The Effect of Health on Earnings: Quasi-Experimental Evidence from Commuting Accidents*
}

\author{
Martin Halla \\ University of Linz \& IZA
}

\author{
MARTINA ZWEIMÜLLER \\ University of Linz
}

\author{
forthcoming in Labour Economics
}

(Last update: February, 2013)

\begin{abstract}
This paper interprets accidents occurring on the way to and from work as negative health shocks to identify the causal effect of health on labor market outcomes. We argue that in our sample of exactly matched injured and non-injured workers, these health shocks (predominantly impairments in the musculoskeletal system) are quasi-randomly assigned. A fixed-effects difference-in-differences approach estimates a negative and persistent effect on subsequent employment and earnings. After initial periods with a higher incidence of sick leave, injured workers are more likely to be unemployed, and a growing share of them leave the labor market via disability retirement. Injured workers who manage to stay in employment incur persistent earnings losses. The effects are somewhat stronger for sub-groups of workers who are typically less attached to the labor market.
\end{abstract}

JEL Classification: I10, J22, D31, J31, J24, J26, J64, J28.

Keywords: Health, employment, earnings.

\footnotetext{
${ }^{*}$ Corresponding author: Martin Halla, Johannes Kepler University of Linz, Department of Economics, Altenbergerstr. 69, 4040 Linz, ph.: +43 702468 8706, fax: +4370 2468 28706, email: martin.halla@jku.at. For helpful comments we would like to thank two anonymous referees and the Editor Bas van der Klaauw. The paper has also benefited from comments and discussions with David Card, Emilia Del Bono, Carlos Dobkin, Marco Francesconi, Nicolas Ziebarth, Gerald Pruckner, Eddy van Doorslaer, Andrea Weber, Rudolf Winter-Ebmer, Josef Zweimüller, as well as from participants at the Annual Meeting 2010 of the Austrian Economic Association in Vienna, at the 2010 Conference of Applied Econometrics Association (Econometrics of Healthy Human Resources) in Rome, at the Annual Conference 2010 of the European Society for Population Economics in Essen, at the 2010 Congress of the European Economic Association in Glasgow, and at the Research Seminar at the University of Innsbruck. The usual disclaimer applies. Moreover, we thank the following institutions for providing us with data: Austrian Workers' Compensation Board, Central Institute for Meteorology and Geodynamics, Main Association of Austrian Social Security Institutions, Upper Austrian Health Insurance Fund, and the Austrian Federal Ministry of Finance. This paper was partly written during Martin Halla's visiting scholarship at the Center for Labor Economics at the University of California at Berkeley. He would like to express his appreciation for the stimulating academic environment at the center and the hospitality he received. This research was funded by the Austrian Science Fund (FWF): National Research Network S103, The Austrian Center for Labor Economics and the Analysis of the Welfare State.
} 


\section{Introduction}

A positive correlation between health and socio-economic status is well documented in social and medical sciences. ${ }^{1}$ However, a considerable debate about the causal underpinnings of this relationship remains. The identification of causal effects has proven to be extremely difficult (Deaton and Paxson, 1998; Goldman, 2001; Fuchs, 2004). Due to the nature of the problem randomized experiments are mostly not feasible and/or not appropriate. Thus, scholars have to rely on natural experiments in order to identify causal effects. ${ }^{2}$ A small number of papers have managed to establish a causal effect of income on health. ${ }^{3}$ In sum, these papers (all studying data from developed countries) find positive but quantitatively small effects of income on (mental) health.

An even smaller number of papers explore the causal effect of health on income. It seems even harder to find and to measure arguably exogenous variation in health compared to income. $\mathrm{Wu}$ (2003) argues that severe health conditions - such as strokes, cancer or diabetes - can be interpreted as exogenous health shocks. In a similar vein, Riphahn (1999) defines a negative health shock as a sudden and substantial drop in subjective health, Wagstaff (2007) uses a substantial drop in the body mass index, and García-Gómez et al. (2011) exploit acute hospitalizations. However, there are some doubts regarding the exogeneity of such events. For instance, Charles (2003) analyzes the dynamic effects of a disability on earnings and finds that earnings have already dropped one year before the onset of the disability. A different approach is given by accidents. Reville and Schoeni (2001) and Crichton, Stillman and Hyslop (2011) study the effects of workplace (and nonworkplace) accidents on employment and income, and Møller Danø (2005) estimates the effect of severe road accidents on labor market outcomes and public transfers. ${ }^{4}$ The evidence presented in these papers is somewhat mixed, which may be explained by varying types of accidents used; however, shows by and large negative effects of accidents on subsequent labor market outcomes.

In this paper, we follow a similar approach; however, we focus on a special type of accident. We interpret accidents occurring on the way to and from work (such as road accidents, slip and fall accidents and injuries due to falling objects) as negative health shocks. This has a number of attractive features: (i) the way to and from work is part of the daily routine of every employed individual and is (in contrast to general road accidents) not affected by leisure time activities, (ii) the likelihood of such a commuting accident is (as compared to a workplace accident) not related to self-selection into certain jobs, offering compensating wage differentials for hazardous workplace environments, (iii) due to an institutional detail of the Austrian mandatory social accident insurance we can observe the universe of commuting accidents in Austria, and link these to the Austrian Social Security Database, a linked employer-employee data-set.

Still, there are some determinants of the likelihood of a commuting accident that may also affect labor market outcomes. Preferences for working at (or close) to home, for living in an urban or rural area, or for certain means of transportation for the work commute (such as train or bike) may

\footnotetext{
${ }^{1}$ For a review of this literature, see, for instance, Strauss and Thomas (1998); Smith (1999).

${ }^{2}$ A notable exception of an experimental setting is given by Thomas et al. (2006).

${ }^{3}$ On an individual-level scholars exploit exogenous variation in income due to inheritances (Meer, Miller and Rosen, 2003), lottery winnings (Lindahl, 2005; Gardner and Oswald, 2007; Apouey and Clark, 2010) and the German reunification (Frijters, Haisken-DeNew and Shields, 2005). Based on cohort data Adda, Banks and von Gaudecker (2009) use changes in income mainly related to changes in the macro-economic environment. The identification of Michaud and van Soest (2008) comes from dynamic linear panel data techniques.

${ }^{4}$ Relatedly, Lindeboom, Llena-Nozal and van der Klaauw (2007) use accidents of any type (reported by survey respondents) as an instrument for disability status to study the effect of a disability on employment.
} 
affect selection into certain jobs. Some of these potential confounding factors are observable in our data. For instance, given an additional link to data from the tax register we observe the commuting distance for each individual. In order to account for remaining unobserved heterogeneity we follow Heckman, Ichimura and Todd (1997) - who have shown that in the presence of longitudinal data, matching and differencing can be fruitfully combined to weaken the underlying assumptions of both methods - and compile a sample of matched treated and control individuals, who share an observationally identical (labor market) history. Thanks to our rich data-before and after the treatment - we can address the usual concerns about this approach. Most importantly, we find strong evidence for a common trend in pre-treatment labor market outcome across injured and non-injured units (common trend assumption). Based on data from a mandatory health insurance, we can further show that the two groups have been following the same trends in objective health outcomes before the treatment. We argue that within our research design commuting accidents are quasi-randomly assigned, and constitute negative health shocks that enable us to establish a causal effect of health on employment and labor market income (henceforth earnings).

Which type of health shocks do commuting accidents generate? While we have no information on the type of injuries in our individual level data, we can resort to aggregate statistics. ${ }^{5}$ These show a wide range of injuries: head and neck (31 percent), trunk (16 percent), upper limbs (11 percent) and lower limbs (18 percent), potentially accompanied by mental stress. That means, our health shocks are predominantly impairments in the musculoskeletal system. Clearly, our research design does not allow us to infer on the effects of typical lifestyle diseases, such as cardiovascular diseases, strokes or cancer. However, it is hard to think of exogenous variation in the incidence of these lifestyle diseases.

Our estimation results show that negative health shocks (i. e., predominantly impairments in the musculoskeletal system) that result in an initial average sick leave spell of 46 days, reduce the likelihood of subsequent employment persistently. Five years after the commuting accident, injured workers are still about four percentage points less likely to be employed. Initially the accident increases the likelihood of sick leave, then injured workers are more likely to be unemployed, and over time a growing share of them leave the labor market via disability retirement. The injured workers who manage to stay in employment experience persistent earnings losses of about minus two percent. The size of the estimated effects varies along the dimensions of sex, occupation, and age. Employment effects are strongest for female, older and blue-collar workers. The highest earnings losses (up to minus three percent) are observed for young workers. While we do not observe much adapting behavior of injured workers in terms of job mobility, we find evidence that injured female workers adjust their fertility behavior in response to the negative health shock.

The remainder of the paper is organized as follows: First, we discuss our research design and outline relevant institutional facts. This section also describes the data and provides descriptive statistics for our estimation samples. The next two sections explain our estimation strategy and discuss the identifying assumption. Subsequently, we present our estimation results for all workers and explore heterogenous treatment effects along the dimensions of sex, occupation and age. We also examine potential adapting behavior and provide a discussion on the channels through which injured individuals leave the labor market. The final section summarizes and concludes the paper.

\footnotetext{
${ }^{5}$ Note, aggregate injury statistics are only available for accidents with subsequent hospitalization and do not distinguish between commuting accidents and all other road accidents. Source: Kuratorium für Verkehrssicherheit. Freizeitunfallstatistik $200 \%$.
} 


\section{Research design}

In Austria, a social accident insurance is mandatory for every employed individual, student and pupil. The Austrian Workers' Compensation Board (AWCB) is the major social accident insurance institution and covers about 76.2 percent of all insurance holders. ${ }^{6}$ In 2007 , the AWCB provided insurance for more than 3.2 million employed individuals, 1.4 million self-employed and 1.3 million students and pupils. Employers have to pay 1.4 percent of the total wage bill to the AWCB, which amounted to 1.1 billion Euro in 2007 (Source: Handbuch der Österreichischen Sozialversicherung 2008). The social accident insurance covers occupational accidents and occupational diseases. Occupational accidents are unexpected external events causing injury, in locational, temporal and causal relationship to the insurant's occupation or education. Occupational diseases are health impairments caused by the insurant's occupation or education and are explicitly listed in the annex to the General Social Insurance Act. Employers (and educational authorities) are bound by law to report every occupational accident and disease to the respective social accident insurance institution. Workers who are disabled as a consequence of an occupational accident (or disease), are eligible for a lifelong disability compensation; which is equal to about two thirds of the earnings in the preceding year (subject to a cap). Partly disabled insurants receive a reduced (pro rata) compensation.

We exploit the fact that accidents occurring on the way between the place of residence and the place of work (or education) are also classified as occupational accidents. We interpret these commuting accidents as negative health shocks and argue that in a sample of exactly matched treated and control workers, this special type of accident is quasi-randomly assigned. ${ }^{7}$ To construct our estimation sample we start with the AWCB Database and retrieve detailed information on all workers who had a commuting accident that occurred between January 1, 2000 and December 31, 2002 and resulted in at least one day of sick leave (treated individuals). In the case workers had two or more commuting accidents during this treatment period, we only consider the first accident as our treatment, since all following accidents may be causally affected by the first incident. Further, we exclude all workers from the analysis who died in the quarter of the accident. ${ }^{8}$ All workers who had no commuting accident during that period serve as potential control units.

The Austrian Social Security Database (ASSD) allows us to follow the treated and the control individuals before, during and after the treatment period (until December 31, 2007). We observe their labor market status in employment (including basic employer information), unemployment, and various other qualifications on a daily basis. The ASSD collects detailed information on all workers in Austria. Since the ASSD is an administrative record to verify pension claims the information is very precise. Information on earnings is provided per year and per employer. The limitations of the data are top-coded wages and the lack of information on working hours (Zweimüller, Winter-Ebmer, Lalive, Kuhn, Wuellrich, Ruf and Büchi, 2009). In combination with the database from the Austrian Federal Ministry of Finance we can compute each individual's

\footnotetext{
${ }^{6}$ Beside the AWCB three other social accident insurance institutions are responsible for special types of selfemployed and employees (and their dependants).

${ }^{7}$ Accidents that occur to workers who are customarily and regularly engaged away from the employer's place of business (e.g. outside sales workers or taxi drivers) are not counted as commuting accidents, except they occur between the place of residence and the central office.

${ }^{8}$ Workers who died later are included until their quarter of death. In our sample, 1.27 percent of treated workers and 1.26 percent of control workers die in the post-treatment period.
} 
commuting distance in kilometers based on the zip code of her place of work and her place of residence. Moreover, the latter database allows us to obtain some information on working hours (i.e. full-time versus part-time employment). Table A.1 in the Appendix A provides an overview of all our data sources.

Our potential control group consists of all workers who have been employed (and insured with the AWCB) at least once during the treatment period (otherwise they have not been at risk to have a commuting accident) and had no commuting accident. In order to distinguish a pre- and post-treatment period for our control units, we randomly assign a quarter between January 1, 2000 and December 31, 2002. If these workers have not been employed in their randomly assigned quarter, we exclude them from our analysis, since information on employment in that quarter is crucial for our matching procedure (see below). To generate a homogenous sample we only consider individuals who were 'regularly' employed in the treatment quarter, i. e. we exclude workers in marginal employment or dependent self-employment. Furthermore, we restrict our analysis to individuals who were employed as either blue-collar or white-collar workers throughout the pretreatment period. ${ }^{9}$ Finally, to guarantee that we can (potentially) observe all individuals before and after the treatment on the labor market we restrict our sample to individuals between 25 and 50 years of age at the time of the (potential) accident.

After applying these sample selection criteria we observe 1.682,602 individuals without an accident, and 11,397 individuals with an accident that resulted at least in one day of sick leave. ${ }^{10}$ We use the length of the sick leave spell after the accident as a proxy for severity. This information is documented in the AWCB database. The distribution of weeks on sick leave is shown in Figure 1. On average, the sick leave spell lasts about four weeks. Half of the individuals spend at least two weeks on sick leave. Clearly, the length of this sick leave spell is an imprecise measure for the severity of the accident, since it might vary with worker's motivation to return to work. This problem is mitigated (at least to some degree) by the fact that sick leave spells longer than three days are subject to medical verification. Moreover, we see in a sub-sample (described in Appendix B) that the sick leave spell length (among the treated) has a very high correlation with health care service utilization. Still, we use the length of the sick leave spell with care and distinguish only between accidents below and above the median, to define individuals with less and more severe accidents. In our main analysis we will concentrate on the sub-set of 5, 909 treated individuals with more severe accidents. ${ }^{11}$ Most of these accidents (almost 65 percent) involve a vehicle. A significant fraction (about 33 percent) is due to slip and fall (e.g. on stairs, ice, snow or slippery ground). The remaining two percent of accidents include, among others, injuries due to falling objects and crushing injuries. That means, the health shocks under consideration are predominantly impairments in the musculoskeletal system.

\footnotetext{
${ }^{9}$ That means that we exclude civil servants, self-employed and farmers. This guarantees that we can observe pre-treatment earnings for all individuals. The ASSD does not provide information on earnings of civil servants; earnings of self-employed and farmers are only recorded since 1997.

${ }^{10}$ About 5,000 individuals had an accident but had zero days of sick leave. We exclude these individuals from our analysis since they obviously had only a minor accident. In an additional estimation analysis, we exploit the idea that this group is not injured, but is supposedly quite comparable to our treatment group. Using them as an alternative control group gives results that are very comparable to those in our main analysis.

${ }^{11}$ In order to check the sensitivity of this sample selection criteria we alternatively used hospitalization to split the sample. Clearly, the hospitalization decision is less discretionary than the amount of sick leave. The estimation results have the same patterns across the two sample selection criteria (compare Table 2 and 3 with Table A.2 and A.3 in the Appendix A) - the employment effects are at a higher level in the latter case, since these are on average more severe accidents.
} 
It should be noted that workers who had an accident during their leisure time have almost no possibility or incentive to cheat and to falsely report that the accident took place on the way to or from work. Employees have to report the accident to the employer without delay, and in case the injured worker needs medical treatment the exact time and date is recorded by the doctor or hospital. Furthermore, irrespective of whether the accident happened on the way to or from work or in leisure time, the health care cost and the compensation for lost earnings caused by temporary sickness are covered by an insurance in either case. ${ }^{12}$ This claim is supported by the distribution of commuting accidents by weekday and daytime (see Figure 2). As expected, most of the accidents take place Monday through Friday, and during rush hours.

Table 1 compares the average characteristics of treated and a random sample of control workers in the quarter of the (potential) accident. Since we measure all characteristics on the first day of each quarter, the quarter of the (potential) accident is the last quarter of the pre-treatment period. The comparison of treated and control individuals (the first two columns) reveals that there are some significant differences in the average characteristics of these two groups. Treated workers have a longer commute (about plus four kilometers). This seems plausible; the longer the way to work the higher the likelihood of a commuting accident. Further, treated individuals are slightly older and more likely female. ${ }^{13}$ The most important difference is in the distribution of occupational groups. The share of blue-collar (white-collar) workers is higher among the treated (control). ${ }^{14}$ Consequently, we find that treated individuals are less likely to have a degree, have somewhat lower earnings, slightly less working experience, and a shorter tenure. A plausible explanation for the higher incidence of commuting accidents among blue-collar workers are different work schedules. Blue-collar workers are more likely to work in a shift system. That means, they have to commute early in the morning or later at night. At these hours unfavorable lightening and road conditions may promote accidents of any kind. ${ }^{15}$ In line with this supposition we see a clear pattern that blue-collar workers accidents' are more likely to happen very early in the morning or later at night (see Figure 2 in the Appendix A). Further differences can be found with respect to the type of employers. Treated individuals tend to work in larger firms and are more likely to be employed in the manufacturing sector. This partly reflects an unequal distribution of blue- and white-collar workers across employers, but also a correlation with the commuting distance. Larger firms (or firms from certain industries) tend to be in peripheral enterprise zones, which implies a comparable longer commute for their employees.

These descriptive statistics suggest that commuting accidents do not happen perfectly randomly, hence we are concerned with selection that might complicate the comparison of treated and

\footnotetext{
${ }^{12}$ Depending on whether the accident is occupational or non-occupational, the health care cost are either covered by the social accident insurance or the social health insurance. In both cases, the compensation for lost earnings (the so-called Entgeltfortzahlung) is initially (i. e. at least eight weeks) disbursed by the employer. After a certain length of sick leave this compensation is covered by the social accident insurance or the social health insurance, respectively. The only important difference is with respect to rehabilitation cost. In case of an occupational accident the social accident insurance may provide special occupational retraining and extra disability benefits.

${ }^{13}$ Notably, the sex distribution of commuting accidents is in stark contrast to that of any other type of accident. In 2002 females accounted only for 20.6 percent of all workplace accidents, 40.9 percent of road accidents, 29.0 percent of sports accident and 45.2 percent of other leisure time accidents. Sources: Kuratorium für Verkehrssicherheit (Unfallstatistik 2002); own calculations based on the AWCB Database.

${ }^{14}$ The distinction between blue- and white-collar workers follows the Austrian legal definition and is recorded in the ASSD. Blue-collar workers typically perform manual labor and are directly involved in the production process. In contrast, white-collar workers are non-manual workers in supervising and administrative jobs.

${ }^{15}$ In fact it is documented that most of the pedestrian and vehicle occupant fatalities occur during the change from daylight to twilight or vice versa (Ferguson, Preusser, Lund, Zador and Ulmer, 1995).
} 
control individuals. To correct for differences between these groups, we perform exact matching based on their labor market history, and apply a DiD approach (based on samples stratified by sex, occupation, and age). After describing our matching procedure and the resulting sample, we will spell out our identifying assumption and discuss potential pitfalls. We will also provide supplementary analyses that substantiate the validity of our identifying assumption.

\section{Empirical strategy}

In the empirical analysis we combine two identification strategies to uncover a causal effect of negative health shocks on labor market outcomes. First, we use exact matching to establish the pre-treatment comparability of the treatment and control group, and second, we apply a DiD estimator on the sample of matched treated and control units. In the context of longitudinal data, the combination of matching and DiD can accommodate (i) differences in observed characteristics, and (ii) differences in unobserved characteristics as long as they are constant over time (Heckman et al., 1997). The $\mathrm{DiD}$ approach requires a common trend assumption, which implies that in absence of the negative health shock the average labor market outcomes of treated and control workers follow parallel paths over time. Since we have data for a long time period before the (potential) treatment we can check the series of average outcomes of the two groups.

Figure 3 shows the employment rate and the average daily wage (conditional on employment) by treatment status. We normalize the quarter of the (potential) accident to zero and observe each worker 20 quarters before and after the treatment. For both groups, the employment rate increases rapidly up to the quarter of the (potential) treatment, when it becomes one, and decreases thereafter. This pattern is a consequence of the fact that we select only workers who were employed in this quarter. As these workers are also more likely to have been in employment in the periods leading to the reference quarter, we observe an increasing (decreasing) employment rate in the quarters preceding (subsequent to) the reference quarter. What is important to notice, is that we observe a common trend in employment among treated and control prior to the quarter of the (potential) treatment. This is clear evidence for a common underlying trend of treated and control units. The observed drop in the employment rate after the (potential) treatment is first evidence for an effect of the health shock on employment. An equivalent picture can be observed for the average daily wage. When analyzing earnings we always restrict our sample to employment spells, since positive earnings are observed only for employed workers. ${ }^{16}$ After the (potential) treatment, we observe a slower wage growth path for treated workers, which is first evidence of a negative effect of the health shock on earnings. Alternatively, Figure A.1 in the Appendix A provides a regression-adjusted graphical depiction that removes the pattern caused by the selection rule.

On the basis of the full sample we perform exact matching of treated and control units. In the quarter of the (potential) treatment individuals must have the same sex, age (13 age groups: $25-26,27-28, \ldots, 49-50$ ), education (no academic degree, engineer, MA/MSc, PhD), region of residence (West, East, South, abroad/missing), industry (agriculture, fishing, mining and energy; manufacturing; construction; wholesale, retail and repair; transport and communication; services; missing) and commuting distance (by quintile group plus additional groups for zero and missing

\footnotetext{
${ }^{16}$ Note, the drop in the average wage in the quarter of the (potential) accident is a consequence of the fact that we restrict our sample to employment spells when looking at wages. In the reference quarter, all workers - also those with the least earnings potential — are employed.
} 
distance). On top of that, in the quarter of the treatment and in each of the three preceding quarters their employment status (employed, not employed), broad occupation (blue-collar, whitecollar), and the log of the deflated daily wage rate (by decile groups plus an additional group for non-employed individuals) must coincide. Further we use their quarter of (potential) treatment as a matching criterion. Since some treated individuals may have more control subjects than others we construct weights that compensate for differences in cell size. ${ }^{17}$

Applying this matching procedure we are able to find at least one control unit for 58 percent of our treated individuals, i.e. our estimation sample consists of 3, 406 treated and 26,734 control units. Columns three and four of Table 1 provide descriptive statistics for the matched sample. While treated and control workers should not differ in the matching variables (e.g. age, daily wage, commuting distance), it is reassuring that differences in characteristics that were not among the matching variables, for instance, experience and tenure, are only minor. The only exception is with respect to firm size; matched treated workers are employed in larger firms than their control counterparts. ${ }^{18}$ In order to see the impact of our matching procedure, one can compare Figure 3 (showing the average employment rate and earnings by treatment status in the full sample) with the equivalent figure for the matched sample (see Figure A.2 in the Appendix A).

Based on this sample we estimate the impact of a negative health shock on labor market outcomes (such as employment and earnings) up to five years after the treatment. To make sure that we partial out potential remaining (un)observed heterogeneity we apply a DiD approach to our sample of exactly matched treated and control units. We start with a simple DiD model:

$$
\text { outcome }_{i t}=\alpha_{0}+\alpha_{1} T_{i}+\alpha_{2} P_{t}+\alpha_{3} P_{t} \times T_{i}+\beta \mathbf{X}_{\mathbf{i}(\mathbf{t})}+\theta_{t}+\epsilon_{i t},
$$

where $i$ denotes workers and $t$ denotes time measured in quarters running from -20 to 20 . In a first step we consider the two outcomes, employment and earnings. To capture employment we use a binary variable equal to one if individual $i$ is employed on the first day of the quarter $t$, and zero otherwise. Earnings are measured by the log of the deflated daily wage rate. The binary variable $T_{i}$ is equal to one if individual $i$ is treated and zero otherwise. The variable $P_{t}$ captures the posttreatment period. For simplicity, we pool in a first step all quarters in the pre-treatment period and in the post-treatment period and use a binary variable instead of a full set of quarter dummies. Further, we control for absolute (calendar) time-fixed effects $\theta_{t}$ (consecutive quarter dummies) and a set of individual characteristics $\mathbf{X}_{\mathbf{i}(\mathbf{t})}$ that comprises age-fixed effects and further characteristics that are predetermined at the quarter of the (potential) treatment. ${ }^{19}$ The parameter of primary interest is $\alpha_{3}$, which gives the estimated causal effect of the negative health shock.

In order to allow for varying effects of the negative health shock over time, we extend the model

\footnotetext{
${ }^{17}$ The weights for treated and controls are constructed as follows: treated have a weight of $w_{i}=1$ and controls have a weight of $w_{i}=\frac{m_{C}^{S}}{m_{T}^{S}} \cdot \frac{m_{C}}{m_{T}}$, where $m_{T}$ and $m_{C}$ are the total number of matched treated and controls, and $m_{T}^{S}$ and $m_{C}^{S}$ are the number of treated and controls in cell $S$.

${ }^{18}$ It can be noted that our estimation results are robust to using firm size as an additional matching criterion. Detailed estimation output is available upon request.

${ }^{19}$ We control for the following characteristics measured in the quarter of the accident: sex, education (no academic degree, engineer, MA/MSc, PhD), citizenship (Austrian, non-Austrian), broad occupation (blue-collar, white-collar), place of residence (nine states), location of firm (nine states plus missing), commuting distance (by quintile group plus additional groups for zero and missing distance), industry of the firm (agriculture, fishing, mining and energy; manufacturing; construction; wholesale, retail and repair; transport and communication; services), firm size (log of the number of employees), tenure (in years), work experience (in years), and the quarter of the (potential) accident.
} 
in the following way

$$
\text { outcome }_{i t}=\alpha_{0}+\alpha_{1} T_{i}+\sum_{r=1}^{20} \gamma^{r} Q^{r}+\sum_{r=1}^{20} \delta^{r} Q^{r} \times T_{i}+\beta \mathbf{X}_{\mathbf{i}(\mathbf{t})}+\theta_{t}+\varepsilon_{i t},
$$

where $Q^{r}$ denotes a series of binary variables equal to one if the treatment has been $r$ quarters ago. This dynamic model allows us to trace out the full dynamic response of employment and earnings to the negative health shock, where the estimated causal effect $r$ quarters after the treatment is given by $\delta^{r}$. We check the robustness of our results by including in both models individual fixed-effects which account for unobserved time-invariant heterogeneity. In this case, the treatment indicator $T_{i}$ and all predetermined characteristics are dropped, and $\mathbf{X}_{\mathbf{i}(\mathbf{t})}$ only comprises age dummies.

\section{Identifying assumption}

The main identifying assumption is that the potential labor market outcomes of treated and controls are independent of the treatment status conditional on observed and time-invariant unobserved characteristics, i. e. the remaining error term is not correlated with the probability to have an accident and potential labor market outcomes.

Under which conditions would this assumption fail? A potential pitfall of our estimation strategy is that a job-loss (or a drop in earnings) causes the accident and not vice versa. Fortunately, we will see below that the effect of the accident on employment (and on earnings) kicks in only with some lag. In other words, the timing of the events strongly rejects the case of reverse causality.

Another source of problems are unobserved confounding factors that vary over time. Put differently, we have to ponder on a third factor that causally affects labor market outcomes and that is also correlated with a higher accident probability. Obviously, there is a plethora of factors promoting an accident. Assignment into treatment may result, for instance, from own inattention, sleepiness, other careless traffic participants, bad weather or lightening conditions, as well as any other form of distraction. Some of these factors are undoubtedly exogenous; a third party's fault or bad weather conditions should not be correlated with the treated individual's subsequent labor market outcomes. However, inattention or sleepiness might be the result of already existing health problems or another drastic personal event that may independently affect labor market outcomes. To be more specific, if (i) another drastic personal event (such as sickness, alcoholism, divorce, or death in family) takes place at the same time, (ii) that is the (only) causal determinant of the observed changes in labor market outcomes, and (iii) that is also causing (or at least correlated) with the accident, our identifying assumption would fail, and we would erroneously conclude that the negative health shock affects labor market outcomes. While a high incidence of such systematic patterns (i. e. all three conditions are fulfilled) seems unlikely, we can not completely rule it out. To substantiate our interpretation that the estimated effects are causally related to the negative health shock, and not caused by any other unobserved personal event, we conduct three supplementary analyses.

First, we look at the effects of the accident on different health outcomes, and compare them with the estimated effects of the accident on labor market outcomes. ${ }^{20}$ The idea is that if the

\footnotetext{
${ }^{20}$ Since data on health outcomes is only available for workers from Upper Austria this analysis is based on a sub-sample of the data. Details on the data, which are derived from the database of the Upper Austrian Health
} 
accident causally affects subsequent labor market outcomes, we should observe dynamic effects of the accident on health outcomes that resemble the dynamic effects of the accident on labor market outcomes over time. Figure 4 depicts the estimated effect of the accident on sick leave for the 20 quarters after the accident, based on the dynamic model, which controls in addition for leads starting at quarter minus 7 . First it can be noted that the coefficients capturing the quarters prior to the accident are individually and jointly statistically insignificant, quantitatively very small (basically zero) and do not exhibit a trend. That means, the timing evidence clearly suggests that the accident causally affects subsequent sick leave. On top of that it rules out that any pre-treatment injury or (arising) illness has triggered the accident (which could also be a potential confounding factor). As expected, in the quarter of the accident we find a huge spike; treated workers are estimated to be 18.6 days (or 490 percent) more on sick leave. This positive effect decreases thereafter, however, is still statistically significant different from zero until one year after the accident. As we will see in detail below, these dynamic effects of the accident on sick leave are perfectly compatible with the estimated effects of the accident on labor market outcomes. The same patterns as in the case of sick leave, can be observed for other health outcomes, such as the incidence of hospitalization and extramural health expenditures. (Details are provided in Appendix B.) In sum, this analysis of health outcomes supports our causal interpretation. The only potential pitfall left is given by an unobserved time-variant confounding factor that exhibits dynamic effects on labor market outcomes that by coincidence resemble the effects of the accident on health outcomes.

In order to provide evidence against the latter case, we look at the effect of less severe accidents. If the accident is indeed the causal determinant of subsequent labor market outcomes, we expect smaller treatment effects in the case of less severe accidents. Relating to the reasoning from above, it seems highly unlikely that less and more severe accidents are consistently correlated with unobserved time-variant confounding factors that have small and larger effects on labor market outcomes (resembling by coincidence the dynamic effects of the accident on health outcomes). The analysis (summarized in Appendix C) indeed shows that less severe accidents are estimated to have less (or no) effects on labor market outcomes.

As a final check, we aim to show that accidents are caused by exogenous events. While it is hard to measure all (or even one) factor, we managed at least to obtain information on local weather and lightening conditions. The regression analysis summarized in Appendix D shows - in line with existing literature (Qiu and Nixon, 2008) - that weather conditions are statistically significant determinants of accidents. For instance, we find that on days with an above average precipitation (i. e. compared to an historical average at this specific location on this specific calendar day) the likelihood of an accident increases for women (men) by 4.4 (2.0) percentage points. This result supports the idea that commuting accidents are driven by exogenous (or random) factors that justify its interpretation as a negative health shock. ${ }^{21}$

\footnotetext{
Insurance Fund, are provided in Appendix B.

${ }^{21}$ We also tried to exploit this exogenous variation in the likelihood of a commuting within an instrumental variable framework. This approach gives qualitatively very similar results (compared to the results based on the estimation strategy explained above), however, the estimated effects are larger in (in absolute terms) and the standard errors increase considerably. Given that the F-statistic on the excluded weather variable in the first stage of our two-stage least square estimation is not sufficiently high (especially for males), we decided not to present these results in more detail.
} 


\section{Estimation results}

This section presents our estimation results in the following way: first, we discuss the findings on the effects of an accident on employment and earnings for all workers. We find that such a negative health shock deteriorates labor market outcomes along any dimension. In a next step, we explore heterogeneous treatment effects across sex, occupation, and age. Then we examine potential adapting behavior of treated workers in terms of job mobility across employers and industries. Finally, we distinguish between different forms of non-employment and show to what extent treated workers leave the labor market through unemployment, retirement and parental leave.

\subsection{Baseline results}

We consistently find that individuals who have experienced a commuting accident are subsequently less likely to be employed, and (conditional on being employed) earn lower wages. Based on our exactly matched sample, the static employment model estimates that treated individuals are on average 3.3 percentage points less likely to be employed in the twenty quarters after the accident. Notably, the estimated coefficients of the OLS and the FE model (see first line in Table 2) are basically identical. We interpret this as evidence that our research design is very clean and that accidents on the way to and from work are exogenous in our context. Based on our full sample we find somewhat larger employment effects (about minus 4.7 percentage points). However, again, the inclusion of individual fixed effects has almost no impact on the estimated coefficients (see Table A.4 in the Appendix A).

The estimation results of the dynamic employment model corroborate the findings of the static model and reveal interesting patterns. The upper panel of Figure 5 shows that treated units are (compared to control units) equally likely to be employed in the quarter of the accident. It seems plausible that employers may hesitate to layoff workers during their sick leave, or more generally, shortly after an accident. However, starting with quarter two after the accident a statistically negative employment effect for treated units can be observed each quarter in the post-treatment period. The timing of the accident and the employment effect provides strong evidence against reverse causality. The largest effect (in absolute terms) can be observed in quarter two after the accident (about minus 4.8 percentage points). Over the following twelve quarters the effect is stable around minus 2.8 percentage points, and from quarter fifteen to twenty the effect is estimated to decrease somewhat again. In sum, these results show that a negative health shock has persistent effects on employment.

When we look at wage effects, we have to restrict our sample to employment spells. It is hard to evaluate whether the resulting sample selection bias is relevant in size. However, it seems plausible to assume that the treated workers who return to employment are positively selected in terms of their willingness to perform. Given that our results discussed below would underestimate the true effect of the negative health shock on wages in absolute terms, since we compare the positively

selected treated workers with the average (or unselected) control workers. When we interpret the estimated effects on wages earnings, we further have to keep in mind that we only observe daily and not hourly wages. Variation in daily wages may result from an effect of the accident on working hours and/or the wage rate. While we have no information on the exact number of working hours, 
we can distinguish (since 2002) between full-time and part-time workers. Since we do not find any significant effect of the accident (for any sub-group) on labor supply at the intensive margins (see, Figure A.3 in the Appendix A), we suggest interpreting the estimated effects as variation in the wage rate.

The static results on wages (see first line in Table 3) reveal that treated individuals are disadvantaged, even if they manage to stay in employment. Conditionally on being employed, specification FE-I suggests that an accident reduces wages by about 1.4 percent. The corresponding OLS estimate is equal to 1.1 percentage points. Based on our full sample we find very similar results (see Table A.5 in the Appendix A). In line with that the corresponding dynamic model (summarized in the lower panel of Figure 5) shows a negative effect that increases from quarter one to quarter six after the accident, and settles at about minus two percentage points thereafter. The vast majority of these coefficients are statistically significant (at least) at the five percent level.

Overall, we interpret these results as evidence that negative health shocks have adverse effects on labor market outcomes, and argue that this evidence establishes a clear causal effect of health on earnings. The persistence of the observed effects is remarkable. Negative health shocks - causing an initial average sick leave of about 46 days - have negative effects on employment and wages which are present even after twenty quarters (or five years). This suggests that injuries cause long-lasting impairments that result in either complete displacement or impede career success. This can be explained by reduced work capacity or productivity. For instance, a back injury from a slip and fall accident might not only limit the effectiveness of a manual worker, but also that of an office worker, who can not sit at a desk for long periods of time anymore. Alternatively, workers may have a reduced willingness to perform after the negative health shock, since they are more concerned about their health. It is also possible, that treated workers miss out on promotion opportunities, or hesitate to change job and forgo other more lucrative career paths.

\subsection{Heterogeneous treatment effects}

Next, we explore heterogenous treatment effects along the dimensions of sex, broad occupation, and age. We are interested whether the causal effect of health on labor market outcomes differs across these sub-groups since they typically differ in important characteristics such as their labor supply elasticity, the type of work (manual vs. non-manual), their firm-specific human capital and their labor market experience. These characteristics may affect the magnitude of the effect of a negative health shock on labor market outcomes. For the interpretation of our estimations results in this section we presume that the severity of the accident is not correlated with the workers' characteristics which are used to split the sample. ${ }^{22}$

Looking at the point estimates (from an equivalent analysis as above) based on the different subsamples (see lines two to five in Table 2), one can see that females are hit harder than males (minus 3.6 vs. 2.9 percentage points), and blue-collar workers are more affected than white collar workers (minus 3.5 vs. 3.0 percentage points). The same patterns can be observed if we split the sample

\footnotetext{
${ }^{22}$ Indeed, we hardly find any differences in the lengths of sick leave spell across sex-occupation groups. They only notable difference is that females (both blue- and white collar workers) have somewhat shorter spells (about minus 5 days). This difference can be explained by the fact that females are less likely to have an accident involving a vehicle and more likely to have a slip and fall accident; the former type of accident results on average in longer sick leave spells. Finally, older workers have longer spells. In this case it is hard to distinguish whether this difference is due to more serve accidents or due to a longer convalescence.
} 
by both, occupation and sex (see lines six to nine in Table 2). Female blue-collar workers suffer the most (minus 3.9 percentage points), and male white-collar workers are affected least (minus 2.1 percentage points). Although the differences are not statically significant at conventional levels, this is suggestive evidence that sub-groups which are typically less attached to the labor market (i. e. females ${ }^{23}$ ), or have on average more unemployment spells (i. e. blue-collar workers), have also a higher likelihood to withdraw from employment as a consequence of a negative health shock. This can be explained by a higher lay-off probability (after a negative health shock); blue-collar workers and part-time workers have less firm-specific human capital and can be substituted more easily. Alternatively, factors that prevent an efficient level of sick leave (i. e. presenteeism), health-care utilization or rehabilitation - such as (perceived) low job security, liquidity constraints, or even information problems - may be more relevant for these sub-groups, and lead to lasting health problems impeding subsequent employment.

The estimation results from the dynamic model are presented stratified by sex and occupation. The results on employment (see Figure 6) are in line with the static results, and provide (especially) in combination with the results on wages (see Figure 7) further insights. Let us consider male workers first. Treated male white-collar workers experience initially (until quarter four) statistically significant negative employment effects, with a low (minus 5.7 percentage points) in quarter two after the accident. For the following twelve quarters the estimated employment effects are still negative, however, not individually statistically significant at the five percent level. Somewhat surprisingly, with quarter sixteen some significant effects kick in again. The results on earnings show that treated male white-collar workers who manage to stay in employment, do not experience (with the exception of quarter two) any statistically significant earnings losses.

Treated male blue-collar workers on the other hand, experience significantly negative employment effects throughout the whole post-treatment period under consideration. Starting with period two, the effect is pretty stable around minus 3.0 percentage points. And for those who stay in employment, we observe (mostly individually statistically significant) also earnings losses between two and three percent. In line with the dynamic earnings results, the corresponding static results in Table 3 (see specification FE-I) show only a statistically significant negative effect on earnings for male blue-collar workers, but not for their white-collar counterparts. An obvious difference between blue- and white-collar workers is the manual nature of their tasks. This may (besides the aforementioned arguments) exacerbate the return to work for blue-collar worker after a negative health shock. Conditional on employment, reduced (physical) working capacity seems to reduce earnings of blue-collar workers. This is also in line with the observation that the output of bluecollar workers is typically more easily observable; for instance (in contrast to white collar-workers) some blue-collar workers are paid by piece rates.

In the case of females, we observe different patterns of heterogenous treatment effects. Somewhat surprisingly, the negative health shock has stronger effects - at least clearly in terms of earnings - on female white-collar workers compared to their blue-collar counterparts. As we know from the static model, both groups are less likely to be employed after the accident. The dynamic model (Figure 7) reveals that for female white-collar workers the effect is (starting with

\footnotetext{
${ }^{23}$ The female labor force participation rate (for women between 15 and 64 years of age) was 63.7 percent in 2002 ; the figure for males was 79.7 percent (Source: Statistics Austria). About 36 percent of the female workforce was employed part-time; compared to only 5 percent of the male workforce (Source: Eurostat Labour Force Survey, 2002).
} 
quarter two) pretty stable around minus four percentage points over the whole post-treatment period. In contrast, the female blue-collar workers' adjustment path is non-monotonic. After the accident (quarter one to five) we see statistically significant effects around minus four percentage points. From quarter six to fourteen, however, the effects (and their significance) decreases in absolute terms. Thereafter, size and significance rise again (up to minus eight percentage points). With respect to earnings statistically significant effects are (in both models) only present for female white-collar workers; the effects increase over time and amount up to minus four percentage points.

The peculiar dynamics of female blue-collar workers' employment effects, as well as the differential patterns of heterogenous treatment effects across sexes, can be explained by adapting behavior (job mobility) and a causal effect of the negative health shock on fertility (to be discussed in detail below). We find that treated female blue-collar workers have a higher incidence of job mobility exactly in quarter six, when the negative employment effects (temporarily) vanish. Moreover, they initially reduce fertility (this increases ceteris paribus their employment) and starting around quarter twelve the trend reverses. The result of stronger earnings effect for treated white-collar workers (compared to their blue-collar counterparts ${ }^{24}$ ) is in line with theoretical arguments suggesting that labor market interruptions are more costly in the case of a job associated with firm-specific human capital compared to a job where more general human capital is decisive (Schwerdt, Ichino, Ruf, Winter-Ebmer and Zweimüller, 2010). Clearly, internal labor markets and career concerns are more important for white-collar than for blue-collar workers, who have typically less discretion at work. However, it is a priori unclear why this effect applies only to female, but not to male workers. A possible explanation for this asymmetry might be differential physical demand at work.

Finally, we explore heterogenous treatment effects along the dimensions of age. Therefore, we define young (below 38 years of age) and old workers (38 years of age and above). The two upper panels of Figure 8 show that older treated workers suffer (compared to younger treated workers) more in terms of negative employment effects. In line with this, the static employment model (see Table 2) estimates a reduced likelihood of employment for older workers of minus 4.1 percentage points, and for younger worker of minus 2.4 percentage points. However, among those treated workers who manage to stay in employment, in fact, only the young workers experience statistically significant earnings losses (see lower panels of Figure 8). Accordingly, the static earnings model gives an average earnings loss for younger workers of 2.8 percent, and for older workers of minus 0.2 percentage points (see Table 3 ). This statistically significant difference by age can be rationalized as follows. On the one hand old workers recover less well ${ }^{25}$ (compared to younger workers), and are probably less attached to the labor market. Both factors make it on average harder for older workers to stay (or to return) to employment. On the other hand, among the treated workers who manage to stay in employment, the young workers are probably those who (have to) forgo promotion opportunities due to persistent impairments, which results in lower wage growth paths. Older workers are on average more likely to be established in their careers, and since demotion is not a common practice, they have only marginal earnings losses (compared to the control counterparts).

\footnotetext{
${ }^{24}$ Notably, the reversion of the negative effect on earnings takes place in quarter six; the quarter with the statistically significant higher incidence of job mobility.

${ }^{25}$ In our estimation sample the duration of sick leave resulting from the accident is on average 48 days for older workers, and 44 days for younger workers.
} 


\subsection{Adapting behavior}

If treated workers are aware that their physical and/or mental impairments reduce their productivity at work - which will eventually lead to less career opportunities, lower wages, or even job loss - they may re-evaluate their career, and consider a change in job, or even in occupation. Therefore, we would expect an increase in job mobility after a negative health shock. Alternatively, treated workers - especially those who still have sufficient work capacity in their current job - may turn risk averse, and hesitate to change job or employer, even if they could expect higher wages or attractive career opportunities. This effect should decrease job mobility among treated workers.

In order to identify any adapting behavior we apply an equivalent estimation strategy as above to examine job mobility of treated workers across firms and industries. In particular, we examine the whole post-treatment period, and estimate the likelihood of an employer or industry change in each quarter. ${ }^{26}$ Overall, we find very little evidence that a negative health shock has any effect on subsequent job mobility. The estimation results of the static model of the likelihood to change employer and industry are summarized (for different sub-groups) in Table 4 . The only sub-group for which we observe consistent statistically significant positive effects are treated female workers; in particular female blue-collar workers. Treated female blue-collar workers are (in a given quarter) about 0.75 percentage points more likely to change their employer and industry (their sample means of employer and industry change are 4.08 and 2.17 percent). For all other sub-groups, the quantitative effects are quite small and insignificant. In sum, we find little evidence for adapting behavior in terms of job mobility. However, in principle, we can not rule out that two opposing effects offset each other.

Given that post-treatment job mobility may be influenced by the treatment, we did not control for workers' post-treatment (occupation or) industry in the estimation results on earnings discussed so far. In principle, if switching occupation or industry has an effect on (the loss of) earnings, then the inclusion of respective control variables should have a discernable impact on the estimated treatment effects. However, since we have just seen that little adapting behavior has taken place, we do not expect much changes in the estimated treatment effects by including these additional covariates. Comparing specification FE-I and FE-II in Table3, where the latter includes also dummies for broad occupation and industry, we indeed do not find any significant differences in the estimated effects across these two specifications. Even female blue-collar workers who are more likely to change their employer and industry after the negative health shock do not benefit from their increased job mobility.

\subsection{Types of non-employment}

We have shown so far that a negative health shock has adverse effects on employment. However, we do not know yet through which channel affected workers leave employment. In principle, this requires the formulation of a multinomial choice model. To simplify things, we proceed in two steps. First, we carry out a descriptive analysis and look at simple weighted differences between treated and control workers. In a second step we focus on specific channels, and apply binary choice models as we have done above.

\footnotetext{
${ }^{26}$ Here, we exclude non-employment spells. If a worker returns subsequently into employment, and s/he returns to the same firm/industry we do note rate this as job mobility.
} 
Figure 9 provides weighted differences of different labor market status between treated and control workers stratified by sex and occupation. As a matter of fact, treated workers are more likely to be on sick leave or rehabilitation after the accident. ${ }^{27}$ This effect peaks around quarter two, shrinks thereafter, and slowly fades out over time. With some delay-compared to the incidence of sick leave - the incidence of unemployment increases and fluctuates over time. For both sexes, the incidence of unemployment is higher among blue-collar workers, and in line with our results from above, basically zero for male white-collar workers. Finally, we see that treated units are comparably more likely to retire (i. e. disability retirement). This effect increases over the whole post-treatment period and amounts to plus two percentage points after twenty quarters for all sub-groups. Taken together, this evidence suggests that part of the treated workers recover over time and manage to stay in regular employment. While others struggle for a while (with periods of sick-leave, rehabilitation and/or unemployment) before they decide/manage to retire.

For treated female blue-collar workers we find an interesting pattern of the probability to be on maternity leave, which allows inference on the impact of the negative health shocks on fertility behavior. To explore this effect in more detail, and to obtain respective confidence intervals, we look at the estimation result from a dynamic model summarized in Figure 10. Treated female bluecollar workers have a statistically lower likelihood of maternity leave until quarter twelve after the accident. Thereafter, the relative incidence of fertility increases again, and eventually turns even positive. How can this inverted U-shaped pattern be explained? The negative health shock may affect fertility through three different channels. First, there may be a direct health effect. Health problems may reduce women's fecundity or willingness to bear children. Second, fertility behavior may respond to the reduced work capacity (or unemployment). Within this domain two effects are possible. The negative health shock may have a substitution effect, since during a period with reduced work capacity (or of unemployment) opportunity cost for having a child decrease. On the other hand, a reduction of earnings (income effect), may reduce the demand for children.

Our results suggest that right after the accident there is clearly no dominant substitution effect. The initial decrease may reflect a direct health effect, an earnings effect (due to reduced employment), or a combination of both. The reversing trend starting in quarter twelve, however, may express a lagging substitution effect. It may take a while for treated workers to realize their disadvantage on the labor market. Alternatively, women simply have an optimal number of children in mind, and they make up for lost chances (e.g. due to a transitory direct health effect after the accident). It is impossible to disentangle these two explanations, but in any case both channels are causally related to the negative health shock. Since we can not observe completed fertility, we can also not ascertain whether the health shock only affects fertility timing, or even the number of ever born children. The absence of this effect for treated female white-collar workers may be explained by less severe effects on earnings and lower direct health effects (i.e. due to higher household earnings and less physical demand at work).

${ }^{27}$ It has to be noted that we observe only longer sick leave spells (i. e. at least nine weeks or longer) in the ASSD. This results from the fact that workers receive their regular salary (so-called Entgeltfortzahlung) after an occupational accident for at least eight weeks directly from their employer, and during this period no documentation in the ASSD is required. (Workers with sixteen years of tenure or more receive their regular salary even for ten weeks.) After this period the sick leave insurance system kicks in, and the sickness benefits (so-called Krankengeld) workers receive are documented in the ASSD. Short sick leave spells (as analyzed in Figure 4) are only documented by the Health Insurance Funds. 


\section{Conclusions}

In this paper, we interpret accidents occurring on the way to and from work as a negative health shock to study the causal effect of health on labor market outcomes. Data from the Austrian mandatory social accident insurance allows us to observe the universe of these accidents which have taken place between 2000 and 2002, and to follow these treated workers (along with exactly matched control workers) before and after the treatment in an exhaustive administrative database.

A fixed-effects difference-in-differences approach (Heckman et al., 1997) shows a persistent negative causal effect of this health shock on employment and earnings. Treated workers - with an initial average sick leave spell of 46 days, predominantly due to impairments in the musculoskeletal system - are significantly less likely to be employed throughout the whole post-treatment period. Even after five years we still find an effect of about minus four percentage points. After initial periods with higher incidence of sick leave (or rehabilitation), treated workers are also more likely to be unemployed, and a growing share of them leave the labor market via disability retirement. Those treated workers, who manage to stay or to return to employment, incur persistent earnings losses. That means negative health shocks may result in either complete withdrawal from employment or impede career success.

The size of the estimated effects varies along the dimensions of sex, occupation, and age. Employment effects are strongest for sub-groups which are traditionally less attached to the labor market, and older workers (who supposedly recover physically less well). The highest earnings losses (about minus three percent) are observed for young workers. Somewhat surprisingly, we do not observe much adapting behavior. Treated workers are only marginally more likely to change job compared to control units. However, we have identified an effect of the negative health shock on fertility behavior. Treated female blue-collar workers initially significantly reduce their fertility. Towards the end of our period under consideration we see, however, an upward trend. Since we can not observe completed fertility, we can not ascertain whether the health shock only affects fertility timing, or even the number of ever born children. More generally, this result indicates that health may have further far-reaching effects on other family outcomes, such as marriage and divorce behavior.

Clearly, the estimated effects have to be interpreted in the light of the Austrian institutional setting, where basically every resident has access to free health-care utilization and rehabilitation. For two other countries - with a comparable Bismarckian (social) health insurance system - there is evidence from a research design based on accidents available. Crichton, Stillman and Hyslop (2011), while using all types of accidents, find for New Zealand very similar results. They also report persistent negative employment effects and a reduction in earnings (conditional on employment); where effects are more pronounced for sub-groups less attached to the labor market. In contrast, Møller Danø (2005), who relies on road accidents in Denmark, finds persistent employment effects only for males. The relative success of the Danish system in re-integrating injured female workers might be explained by the comparable high ratio of public sector employees among females.

Unfortunately, there is no evidence available yet for countries with less pronounced social insurance systems (such as in the U.S.). On the hand negative health shocks may have even more detrimental effects on labor outcomes since liquidity constraints may prevent sufficient health treatment. On the other hand, comparable less generous compensation payments in the case of 
sickness (such as sick leave benefits or disability pensions) may increase treated workers' incentive to re-integrate in the labor market. In future research, it would be revealing to compare the effect of health on earnings under different social security arrangements (see García-Gómez, 2011). This may help to optimize the design of social insurance policies and to set the right compensation benefits level with respect to the trade-off between sufficient protection against the risk of negative health shocks and minimizing moral hazard.

That means the identification of the causal paths between health and earnings is not a purely intellectual exercise, but has far-reaching implications beyond the ivory tower of academia. Causal interpretations are also necessary to guide health and redistribution policy, or to make ethical judgments on (health) inequality (Deaton, 2011). Having established the causal link between health and earnings, one can argue that policies to reduce health inequality will also help to reduce income inequality - an externality, efficient policy design has to take into account. Finally, it will help to improve our understanding of the deeper mechanism of the accumulation of human capital and inter-generational mobility.

\section{References}

Adda, Jérôme, James Banks and Hans-Martin von Gaudecker (2009), 'The Impact of Income Shocks on Health: Evidence from Cohort Data', Journal of the European Economic Association 7(6), 1361-1399.

Apouey, Bénédicte and Andrew E. Clark (2010), Winning Big but Feeling No Better? The Effect of Lottery Prizes on Physical and Mental Health, IZA Discussion Paper 4730, Institute for the Study of Labor (IZA), Bonn (Germany).

Charles, Kerwin K. (2003), 'The Longitudinal Structure of Earnings Losses Among Work-Limited Disabled Workers', Journal of Human Resources 38(3), 618-646.

Crichton, Sarah, Steven Stillman and Dean Hyslop (2011), 'Returning to Work from Injury: Longitudinal Evidence on Employment and Earnings', Industrial and Labor Relations Review 64(4), 765-785.

Deaton, Angus (2011), What does the Empirical Evidence tell us about the Injustice of Health Inequalities?, Unpublished manuscript, Center for Health and Wellbeing, Princeton University.

Deaton, Angus S. and Christina H. Paxson (1998), 'Aging and Inequality in Income and Health', American Economic Review 88(2), 248-253.

Ferguson, Susan A., David F. Preusser, Adrian K. Lund, Paul L. Zador and Robert G. Ulmer (1995), 'Daylight Saving Time and Motor Vehicle Crashes: The Reduction in Pedestrian and Vehicle Occupant Fatalities', American Journal of Public Health 85(1), 92-95.

Frijters, Paul, John P. Haisken-DeNew and Michael A. Shields (2005), 'The Causal Effect of Income on Health: Evidence from German Reunification', Journal of Health Economics 24(5), 997-1017.

Fuchs, Victor R (2004), 'Reflections on the Socio-Economic Correlates of Health', Journal of Health Economics 23(4), 653-661. 
García-Gómez, Pilar (2011), 'Institutions, Health Shocks and Labour Market Outcomes Across Europe', Journal of Health Economics 30(1), 200-213.

García-Gómez, Pilar, Hans van Kippersluis, Owen O'Donnella and Eddy van Doorslaer (2011), Effects of Health on Own and Spousal Employment and Income using Acute Hospital Admissions, Discussion Paper 143/3, Tinbergen Institute.

Gardner, Jonathan and Andrew J. Oswald (2007), 'Money and Mental Wellbeing: A Longitudinal Study of Medium-Sized Lottery Wins', Journal of Health Economics 26(1), 49-60.

Goldman, Noreen (2001), Social Inequalities in Health: Disentangling the Underlyng Mechanisms, in M.Weinstein, M. A.Stoto and A. I.Hermalin, eds, 'Population Health and Aging: Strengthening the Dialogue between Demography and Epidemiology', Annals of the New York Academy of Science, New York Academy of Sciences, New York, pp. 118-139.

Heckman, James, Hideniko Ichimura and Petra Todd (1997), 'Matching as an Economic Evaluation Estimator: Evidence from Evaluating a Job Training Program', Review of Economic Studies 64(4), 605-654.

Lindahl, Mikael (2005), 'Estimating the Effect of Income on Health and Mortality Using Lottery Prizes as Exogenous Source of Variation in Income', Journal of Human Resources 40(1), 144-168.

Lindeboom, Maarten, Ana Llena-Nozal and Bas van der Klaauw (2007), Health Shocks, Disability and Work. Unpublished manuscript, Department of Economics, Free University Amsterdam.

Meer, Jonathan, Douglas L. Miller and Harvey S. Rosen (2003), 'Exploring the Health-Wealth Nexus', Journal of Health Economics 22(5), 713-730.

Michaud, Pierre-Carl and Arthur van Soest (2008), 'Health and Wealth of Elderly Couples: Causality Tests Using Dynamic Panel Data Models', Journal of Health Economics 27(5), 1312-1325.

Møller Danø, Anne (2005), 'Road Injuries and Long-Run Effects on Income and Employment', Health Economics 14(9), 955-970.

Qiu, Lin and Wilfrid A. Nixon (2008), 'Effects of Adverse Weather on Traffic Crashes: Systematic Review and Meta-Analysis', Transportation Research Record: Journal of the Transportation Research Board 2055, 139-146.

Reville, Robert T. and Robert F. Schoeni (2001), 'Disability From Injuries at Work: The Effects on Earnings and Employment'. RAND Corporation Publications Department, Working paper 01-08.

Riphahn, Regina T. (1999), 'Income and Employment Effects of Health Shocks. A Test Case for the German Welfare State', Journal of Population Economics 12(3), 363-389.

Schwerdt, Guido, Andrea Ichino, Oliver Ruf, Rudolf Winter-Ebmer and Josef Zweimüller (2010), 'Does the Color of the Collar Matter? Employment and Earnings after Plant Closure', Economic Letters 108(2), 137-140. 
Smith, James P. (1999), 'Healthy Bodies and Thick Wallets: The Dual Relation Between Health and Economic Status', Journal of Economic Perspectives 13(2), 145-166.

Strauss, John and Duncan Thomas (1998), 'Health, Nutrition, and Economic Development', Journal of Economic Literature 36(2), 766-817.

Thomas, Duncan, Elizabeth Frankenberg, Jed Friedman, Jean-Pierre Habicht, Mohammed Hakimi, Nicholas Ingwersen, Jaswadi, Nathan Jones, Christopher McKelvey, Gretel Pelto, Bondan Sikoki, Teresa Seeman, James P. Smith, Cecep Sumantri, Wayan Suriastini and Siswanto Wilopo (2006), Causal Effect of Health on Labor Market Outcomes: Experimental Evidence, On-Line Working Paper Series 070, California Center for Population Research.

Wagstaff, Adam (2007), 'The Economic Consequences of Health Shocks: Evidence from Vietnam', Journal of Health Economics 26(1), 82-100.

Wu, Stephen (2003), 'The Effects of Health Events on the Economic Status of Married Couples', Journal of Human Resources 38(1), 219-230.

Zweimüller, Josef, Rudolf Winter-Ebmer, Rafael Lalive, Andreas Kuhn, Jean-Philipe Wuellrich, Oliver Ruf and Simon Büchi (2009), The Austrian Social Security Database (ASSD), Working Paper 0901, The Austrian Center for Labor Economics and the Analysis of the Welfare State, University of Linz. 


\section{Tables and Figures}

Table 1: Average characteristics by treatment status in the quarter of the accident ${ }^{a}$

Female

Blue-collar

Age

Academic degree

Non-Austrian citizenship ${ }^{c}$

Tenure (in years) ${ }^{c}$

Experience (in years) ${ }^{c}$

Real daily wage (in Euro)

Commuting distance (in $\mathrm{km}$ )

Region of residence:

West (NUTS 1)

East (NUTS 2)

South (NUTS 3)

Abroad or unknown

Firm size : $^{2}$

Overall mean

1 to 9

10 to 49

50 to 99

100 to 499

500 or more

Industry of employer:

Agriculture, fishing, mining \& energy

Manufacturing

Construction

Wholesale, retail \& repair

Transport \& communication

Services

Probability of long sick leave (pre-treatment) ${ }^{d}$

Sick leave resulting from accident (in days) ${ }^{e}$

Full sample

Control Treatment Signif. Control Treatment Signif. group

$(N=16,813)$

group

group

of

0.46

0.45

37.03

0.05

0.25

5.90

15.03

81.48

27.83

$N=5,909)$

diff.

$(N=$

$=26,73$

0.59

0.59
37.29

$* * *$

0.57

** $\quad 37.69$

0.02

0.25

5.50

$* * *$

37.69
0.01

0.27

14.89

77.54

***

15.83

$\begin{array}{lll}* * * & 79.06\end{array}$

$\begin{array}{ll}* * * & 25.93\end{array}$

$N=3,406) \quad$ diff.

0.51

0.57

37.68

0.01

0.25

6.61

15.58

79.12

26.13

$\begin{array}{lllll}0.37 & 0.35 & * * & 0.35 & 0.35 \\ 0.42 & 0.40 & * * & 0.43 & 0.43 \\ 0.21 & 0.25 & * * * & 0.22 & 0.22 \\ 0.01 & 0.00 & * * & 0.00 & 0.00\end{array}$

\subsection{4 \\ 0.17 \\ 0.24 \\ 0.10}

1724.71

\subsection{8}

$* * *$

$* * *$

1563.61

2114.93

0.07

0.16

$* * *$

0.15

0.20

0.10

***

0.26

0.34

$* * *$

0.30

0.14

0.10

0.32

0.38

$\begin{array}{ccccc}0.02 & 0.02 & * * * & 0.01 & 0.01 \\ 0.23 & 0.27 & * * * & 0.29 & 0.29 \\ 0.08 & 0.08 & & 0.06 & 0.06 \\ 0.18 & 0.15 & * * * & 0.12 & 0.12 \\ 0.06 & 0.05 & * & 0.03 & 0.03 \\ 0.43 & 0.44 & & 0.49 & 0.49 \\ 0.01 & 0.01 & & 0.01 & 0.01 \\ - & 48.4 & & - & 45.9\end{array}$

${ }^{a}$ This table provides the average characteristics of all individuals by treatment status measured on the first day of the quarter of the (placebo) accident in the full sample and in the matched sample. $*, * *$ and $* * *$ indicate statistical significance of the difference in the average characteristics at the 10-percent level, 5-percent level, and 1-percent level, respectively. ${ }^{b}$ Exact matching of treated and control units is based on the following characteristics measured on the first day of the quarter of the (placebo) accident: sex, age (13 age groups: $25-26,27-28, \ldots, 49-50$ ), education (no academic degree, engineer, MA/MSc, $\mathrm{PhD}$ ), region of residence (West, East, South, abroad/missing), industry (agriculture, fishing, mining and energy; manufacturing; construction; wholesale, retail and repair; transport and communication; services) and commuting distance (by quintile group plus additional groups for zero and missing distance). Note, engineer ('Ing.') is a legally protected professional title that is granted to graduates from higher vocational schools with technical orientation after three years of work experience. Further criteria are the employment status (employed, not employed), broad occupation (blue-collar, white-collar), and the log of the deflated daily wage rate (by decile groups plus an additional group for non-employed individuals) in the quarter of the treatment and in each of the three preceding quarters. Further we use the quarter of the (placebo) accident as a matching criterion. Note, some treated subjects may have more control subjects than others; to account for that weights are used. ${ }^{c}$ Characteristic has not been matching criteria. ${ }^{d}$ See, footnote 27 for a definition of long (vs. short) sick leave spells. ${ }^{e}$ This information is provided in the AWCB Database. 
Table 2: The effect of an accident on employment ${ }^{a}$

\begin{tabular}{|c|c|c|}
\hline & OLS & FE-I \\
\hline $\begin{array}{l}\text { ALL WORKERS } \\
(N=1.231,822)\end{array}$ & $\begin{array}{l}-3.25 \% * * * \\
(0.55)\end{array}$ & $\begin{array}{l}-3.26 \% * * * \\
(0.55)\end{array}$ \\
\hline $\begin{array}{l}\text { MALE WORKERS } \\
(N=471,242)\end{array}$ & $\begin{array}{l}-2.84 \% * * * \\
(0.65)\end{array}$ & $\begin{array}{l}-2.85 \% * * * \\
(0.65)\end{array}$ \\
\hline $\begin{array}{l}\text { FEMALE WORKERS } \\
(N=760,580)\end{array}$ & $\begin{array}{l}-3.63 \% * * * \\
(0.87)\end{array}$ & $\begin{array}{l}-3.64 \% * * * \\
(0.87)\end{array}$ \\
\hline $\begin{array}{l}\text { BLUE-COLLAR WORKERS } \\
(N=671,158)\end{array}$ & $\begin{array}{l}-3.46 \% * * * \\
(0.75)\end{array}$ & $\begin{array}{l}-3.48 \% * * * \\
(0.75)\end{array}$ \\
\hline $\begin{array}{l}\text { WHITE-COLLAR WORKERS } \\
(N=560,664)\end{array}$ & $\begin{array}{l}-2.98 \% * * * \\
(0.80)\end{array}$ & $\begin{array}{l}-2.98 \% * * * \\
(0.80)\end{array}$ \\
\hline $\begin{array}{l}\text { MALE BLUE-COLLAR WORKERS } \\
(N=284,095)\end{array}$ & $\begin{array}{l}-3.15 \% * * * \\
(0.81)\end{array}$ & $\begin{array}{l}-3.17 \% * * * \\
(0.81)\end{array}$ \\
\hline $\begin{array}{l}\text { FEMALE BLUE-COLLAR WORKERS } \\
(N=387,063)\end{array}$ & $\begin{array}{l}-3.89 \% * * * \\
(1.42)\end{array}$ & $\begin{array}{l}-3.91 \% * * * \\
(1.42)\end{array}$ \\
\hline $\begin{array}{l}\text { MALE WHITE-COLLAR WORKERS } \\
(N=187,147)\end{array}$ & $\begin{array}{l}-2.07 \% * * * \\
(1.02)\end{array}$ & $\begin{array}{l}-2.07 \% * * * \\
(1.03)\end{array}$ \\
\hline $\begin{array}{l}\text { FEMALE WHITE-COLLAR WORKERS } \\
(N=373,517)\end{array}$ & $\begin{array}{l}-3.40 \% * * * \\
(1.08)\end{array}$ & $\begin{array}{l}-3.41 \% * * * \\
(1.08)\end{array}$ \\
\hline $\begin{array}{l}\text { YOUNG WORKERS } \\
(N=541,269)\end{array}$ & $\begin{array}{l}-2.38 \% * * * \\
(0.86)\end{array}$ & $\begin{array}{l}-2.40 \% * * * \\
(0.86)\end{array}$ \\
\hline $\begin{array}{l}\text { OLD WORKERS } \\
(N=690,553)\end{array}$ & $\begin{array}{l}-4.08 \% * * * \\
(0.69)\end{array}$ & $\begin{array}{l}-4.09 \% * * * \\
(0.69)\end{array}$ \\
\hline Individual fixed effects & No & Yes \\
\hline Age fixed effects & Yes & Yes \\
\hline Quarter fixed effects & Yes & Yes \\
\hline Further covariates (measured at time $\left.t_{0}\right)^{b}$ & Yes & No \\
\hline
\end{tabular}

$\overline{a \text { This table summarizes estimation results of the effect of a commut- }}$ ing accident on subsequent employment (covering twenty quarters after the treatment) stratified by different groups (see lines) and based on two different specifications (see columns). Each entry reflects a separate estimations, where the dependent variable is equal to one if the individual is employed on the first day of the quarter, and zero otherwise. Estimated using a difference-in-differences approach based on an exactly matched sample of treated and control units, where weights account for the fact that treated units may have more than one control subject. Listed coefficients are reported as the percentage point change in the probability of being employed due to a commuting accident. Robust standard errors (allowing for clustering by individuals and heteroskedasticity of unknown form) are in parentheses below. $*, * *$ and $* * *$ indicate statistical significance at the 10-percent level, 5-percent level, and 1-percent level, respectively. ${ }^{b}$ The set of further covariates includes the following information measured on the first day $\left(t_{0}\right)$ of the quarter of the commuting accident: sex, education (no academic degree, engineer, MA/MSc, PhD), citizenship (Austrian, non-Austrian), broad occupation (blue-collar, white-collar), place of residence (nine states), location of firm (nine states plus missing), commuting distance (by quintile group plus an additional groups for zero and missing distance), industry of the firm (agriculture, fishing, mining and energy; manufacturing; construction; wholesale, retail and repair; transport and communication; services), firm size (log of the number of employees), tenure (in years), work experience (in years), and the quarter of the (placebo) accident. 
Table 3: The effect of an accident on earnings ${ }^{a}$

\begin{tabular}{|c|c|c|c|}
\hline & OLS & FE-I & FE-II \\
\hline $\begin{array}{l}\text { ALL WORKERS } \\
(N=1.108,741)\end{array}$ & $\begin{array}{l}-1.13 \% * * \\
(0.47)\end{array}$ & $\begin{array}{l}-1.40 \% * * * \\
(0.44)\end{array}$ & $\begin{array}{l}-1.46 \% * * * \\
(0.40)\end{array}$ \\
\hline $\begin{array}{l}\text { MALE WORKERS } \\
(N=441,278)\end{array}$ & $\begin{array}{l}-1.10 \% * \\
(0.62)\end{array}$ & $\begin{array}{l}-1.23 \% * * \\
(0.59)\end{array}$ & $\begin{array}{l}-1.22 \% * * \\
(0.50)\end{array}$ \\
\hline $\begin{array}{l}\text { FEMALE WORKERS } \\
(N=667,463)\end{array}$ & $\begin{array}{l}-1.12 \% \\
(0.71)\end{array}$ & $\begin{array}{l}-1.58 \% * * \\
(0.66)\end{array}$ & $\begin{array}{l}-1.69 \% * * * \\
(0.62)\end{array}$ \\
\hline $\begin{array}{l}\text { BLUE-COLLAR WORKERS } \\
(N=598,028)\end{array}$ & $\begin{array}{l}-1.25 \%^{*} \\
(0.64)\end{array}$ & $\begin{array}{l}-1.36 \% * * \\
(0.61)\end{array}$ & $\begin{array}{l}-1.01 \% * \\
(0.52)\end{array}$ \\
\hline $\begin{array}{l}\text { WHITE-COLLAR WORKERS } \\
(N=510,713)\end{array}$ & $\begin{array}{l}-1.08 \% \\
(0.70)\end{array}$ & $\begin{array}{l}-1.56 \% * * \\
(0.64)\end{array}$ & $\begin{array}{l}-2.05 \% * * * \\
(0.59)\end{array}$ \\
\hline $\begin{array}{l}\text { MALE BLUE-COLLAR WORKERS } \\
(N=263,291)\end{array}$ & $\begin{array}{l}-1.59 \% * * \\
(0.78)\end{array}$ & $\begin{array}{l}-1.73 \% * * \\
(0.74)\end{array}$ & $\begin{array}{l}-1.21 \% * * \\
(0.61)\end{array}$ \\
\hline $\begin{array}{l}\text { FEMALE BLUE-COLLAR WORKERS } \\
(N=334,737)\end{array}$ & $\begin{array}{l}-0.53 \% \\
(1.11)\end{array}$ & $\begin{array}{l}-0.65 \% \\
(1.04)\end{array}$ & $\begin{array}{l}-0.51 \% \\
(0.97)\end{array}$ \\
\hline $\begin{array}{l}\text { MALE WHITE-COLLAR WORKERS } \\
(N=177,987)\end{array}$ & $\begin{array}{l}-0.13 \% \\
(0.01)\end{array}$ & $\begin{array}{l}-0.19 \% \\
(0.95)\end{array}$ & $\begin{array}{l}-1.10 \% \\
(0.82)\end{array}$ \\
\hline $\begin{array}{l}\text { FEMALE WHITE-COLLAR WORKERS } \\
(N=332,726)\end{array}$ & $\begin{array}{l}-1.48 \% \\
(0.92)\end{array}$ & $\begin{array}{l}-2.25 \% * * * \\
(0.84)\end{array}$ & $\begin{array}{l}-2.55 \% * * * \\
(0.80)\end{array}$ \\
\hline $\begin{array}{l}\text { YOUNG WORKERS } \\
(N=469,235)\end{array}$ & $\begin{array}{l}-2.20 \% * * * \\
(0.79)\end{array}$ & $\begin{array}{l}-2.54 \% * * * \\
(0.75)\end{array}$ & $\begin{array}{l}-2.82 \% * * * \\
(0.66)\end{array}$ \\
\hline $\begin{array}{l}\text { OLD WORKERS } \\
(N=639,506)\end{array}$ & $\begin{array}{l}-0.15 \% \\
(0.55)\end{array}$ & $\begin{array}{l}-0.38 \% \\
(0.50)\end{array}$ & $\begin{array}{l}-0.21 \% \\
(0.46)\end{array}$ \\
\hline Individual fixed effects & No & Yes & Yes \\
\hline Age fixed effects & Yes & Yes & Yes \\
\hline Quarter fixed effects & Yes & Yes & Yes \\
\hline Further covariates measured at $t_{0}{ }^{b}$ & Yes & No & No \\
\hline Further covariates measured at $t_{x}^{c}$ & No & No & Yes \\
\hline
\end{tabular}

$\bar{a}$ This table summarizes estimation results of the effect of a commuting accident on the subsequent daily wage rate (covering twenty quarters after the treatment) stratified by different groups (see lines) and based on three different specifications (see columns). Each entry reflects a separate estimation using all quarters where individuals have been employed. The dependent variable is equal to the $\log$ of the deflated daily wage rate. Estimated using a difference-in-differences approach based on an exactly matched sample of treated and control units, where weights account for the fact that treated individuals may have more than one control subject. Listed coefficients are reported as the percent change in the daily wage rate due to a commuting accident. Robust standard errors (allowing for clustering by individuals and heteroskedasticity of unknown form) are in parentheses below. *, ** and $* * *$ indicate statistical significance at the 10-percent level, 5-percent level, and 1-percent level, respectively. ${ }^{b}$ This set of further covariates measured on the first day $\left(t_{0}\right)$ of the quarter of the commuting accident includes the following information: sex, education (no academic degree, engineer, MA/MSc, PhD), citizenship (Austrian, non-Austrian), broad occupation (bluecollar, white-collar), place of residence (nine states), location of firm (nine states plus missing), commuting distance (by quintile group plus an additional groups for zero and missing distance), industry of the firm (agriculture, fishing, mining and energy; manufacturing; construction; wholesale, retail and repair; transport and communication; services), firm size (log of the number of employees), tenure (in years), work experience (in years), and the quarter of the (placebo) accident. ${ }^{c}$ This set of time-varying covariates measured on the first day of each quarter includes the following information: broad occupation (blue-collar, white-collar) and the industry of the firm (agriculture, fishing, mining and energy; manufacturing; construction; wholesale, retail and repair; transport and communication; services). 
Table 4: The effect of an accident on job-mobility ${ }^{a}$

\begin{tabular}{|c|c|c|}
\hline & $\begin{array}{l}\text { EMPLOYER } \\
\text { CHANGE }\end{array}$ & $\begin{array}{l}\text { INDUSTRY } \\
\text { CHANGE }\end{array}$ \\
\hline $\begin{array}{l}\text { ALL WORKERS } \\
(N=1.108,741)\end{array}$ & $\begin{array}{l}0.21 \% \\
(0.16)\end{array}$ & $\begin{array}{l}0.18 \% \\
(0.12)\end{array}$ \\
\hline $\begin{array}{l}\text { MALE WORKERS } \\
(N=441,278)\end{array}$ & $\begin{array}{l}-0.06 \% \\
(0.24)\end{array}$ & $\begin{array}{l}0.05 \% \\
(0.17)\end{array}$ \\
\hline $\begin{array}{l}\text { FEMALE WORKERS } \\
(N=667,463)\end{array}$ & $\begin{array}{l}0.51 \% * * \\
(0.22)\end{array}$ & $\begin{array}{l}0.32 \% * \\
(0.18)\end{array}$ \\
\hline $\begin{array}{l}\text { BLUE-COLLAR WORKERS } \\
(N=598,028)\end{array}$ & $\begin{array}{l}0.09 \% \\
(0.24)\end{array}$ & $\begin{array}{l}0.24 \% \\
(0.18)\end{array}$ \\
\hline $\begin{array}{l}\text { WHITE-COLLAR WORKERS } \\
(N=510,713)\end{array}$ & $\begin{array}{l}0.37 \% * \\
(0.21)\end{array}$ & $\begin{array}{l}0.10 \% \\
(0.16)\end{array}$ \\
\hline $\begin{array}{l}\text { MALE BLUE-COLLAR WORKERS } \\
(N=263,291)\end{array}$ & $\begin{array}{l}-0.27 \% \\
(0.31)\end{array}$ & $\begin{array}{l}-0.04 \% \\
(0.22)\end{array}$ \\
\hline $\begin{array}{l}\text { FEMALE BLUE-COLLAR WORKERS } \\
(N=334,737)\end{array}$ & $\begin{array}{l}0.76 \% * * \\
(0.38)\end{array}$ & $\begin{array}{l}0.74 \% * * \\
(0.31)\end{array}$ \\
\hline $\begin{array}{l}\text { MALE WHITE-COLLAR WORKERS } \\
(N=177,987)\end{array}$ & $\begin{array}{l}0.41 \% \\
(0.34)\end{array}$ & $\begin{array}{l}0.25 \% \\
(0.26)\end{array}$ \\
\hline $\begin{array}{l}\text { FEMALE WHITE-COLLAR WORKERS } \\
(N=332,726)\end{array}$ & $\begin{array}{l}0.34 \% \\
(0.27)\end{array}$ & $\begin{array}{l}0.02 \% \\
(0.21)\end{array}$ \\
\hline $\begin{array}{l}\text { YOUNG WORKERS } \\
(N=469,235)\end{array}$ & $\begin{array}{l}0.22 \% \\
(0.27)\end{array}$ & $\begin{array}{l}0.20 \% \\
(0.21)\end{array}$ \\
\hline $\begin{array}{l}\text { OLD WORKERS } \\
(N=639,506)\end{array}$ & $\begin{array}{l}0.20 \% \\
(0.19)\end{array}$ & $\begin{array}{l}0.15 \% \\
(0.14)\end{array}$ \\
\hline Individual fixed effects & Yes & Yes \\
\hline Age fixed effects & Yes & Yes \\
\hline Quarter fixed effects & Yes & Yes \\
\hline
\end{tabular}

$\bar{a}$ This table summarizes estimation results of the effect of a commuting accident on subsequent job mobility across firms (first column) and across industries (second column). Each entry reflects a separate estimation using all quarters where individuals have been employed. The dependent variable is equal to one if the individual is changing employer/industry, and zero otherwise. Estimated using a differencein-differences approach based on an exactly matched sample of treated and control units, where weights account for the fact that treated units may have more than one control subject. Listed coefficients are reported as the percentage point change in the probability of being employed due to a commuting accident. Robust standard errors (allowing for clustering by individuals and heteroskedasticity of unknown form) are in parentheses below. ${ }^{*},{ }^{*}$ and ${ }^{* * *}$ indicate statistical significance at the 10-percent level, 5-percent level, and 1-percent level, respectively. 
Figure 1: Distribution of commuting accidents by weeks on sick leave

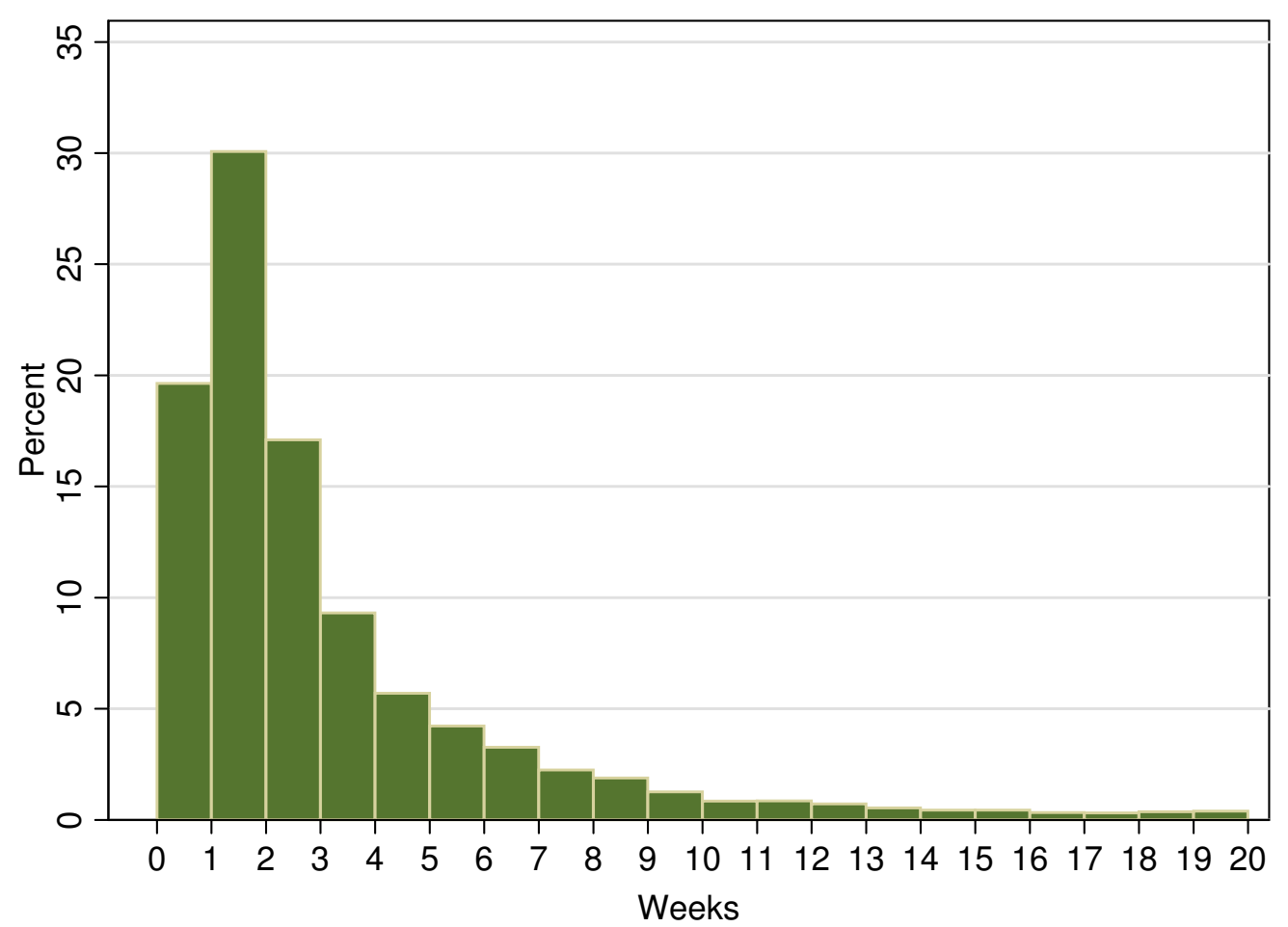

Notes: $N=11,397$, Median $=2$, Mean $=4.1$, S.D. $=6.8, \operatorname{Min}=0.14, \operatorname{Max}=89$. 
Figure 2: Distribution of commuting accidents by weekday and daytime (stratified by sex-occupation group) ${ }^{a}$
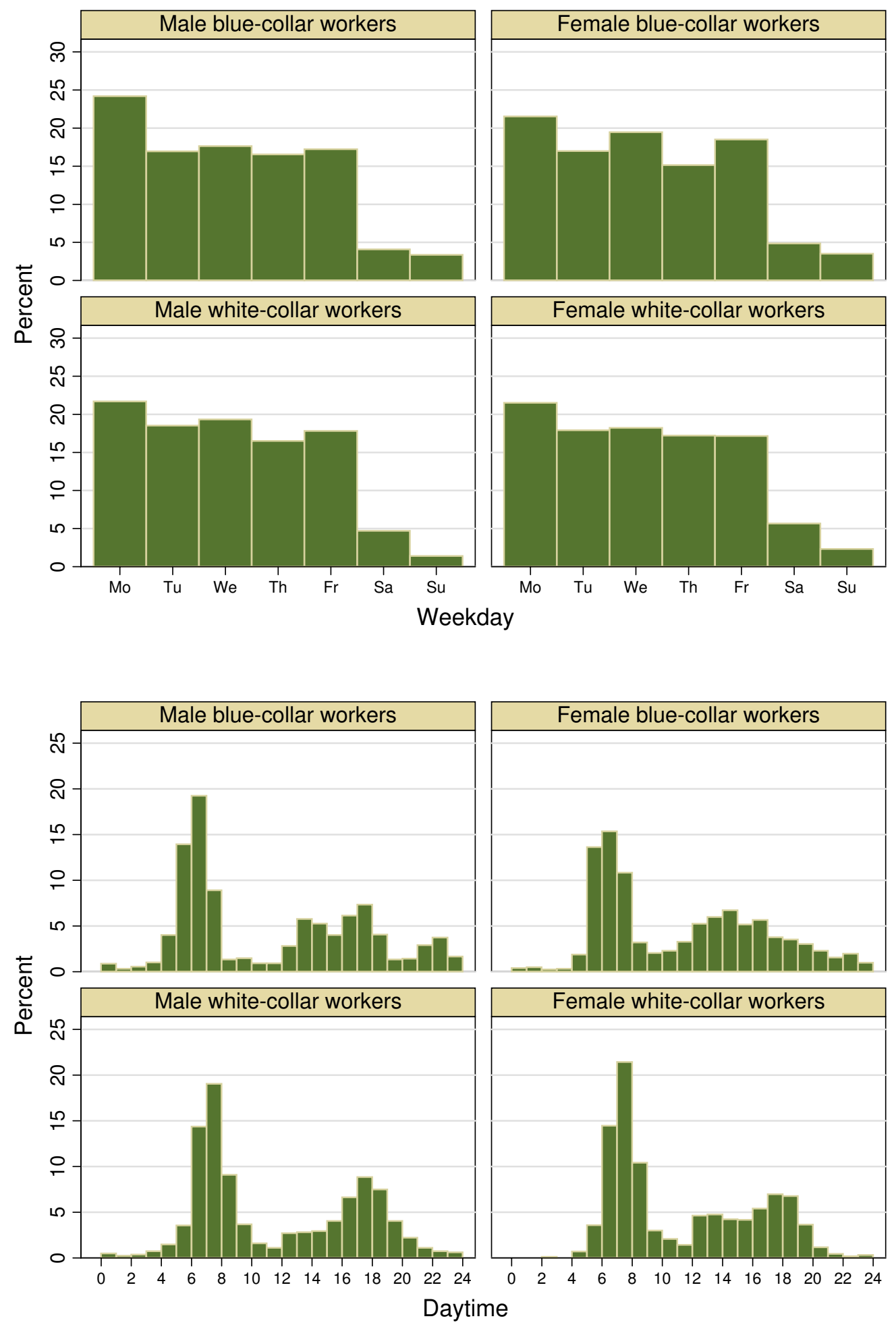

${ }^{a}$ These graphs show the distribution of commuting accidents by weekday (upper panel) and daytime (lower panel) based on the sample of the 5,909 treated individuals with a least two weeks of sick leave after the commuting accident. 
Figure 3: Employment rate and earnings by treatment status ${ }^{a}$
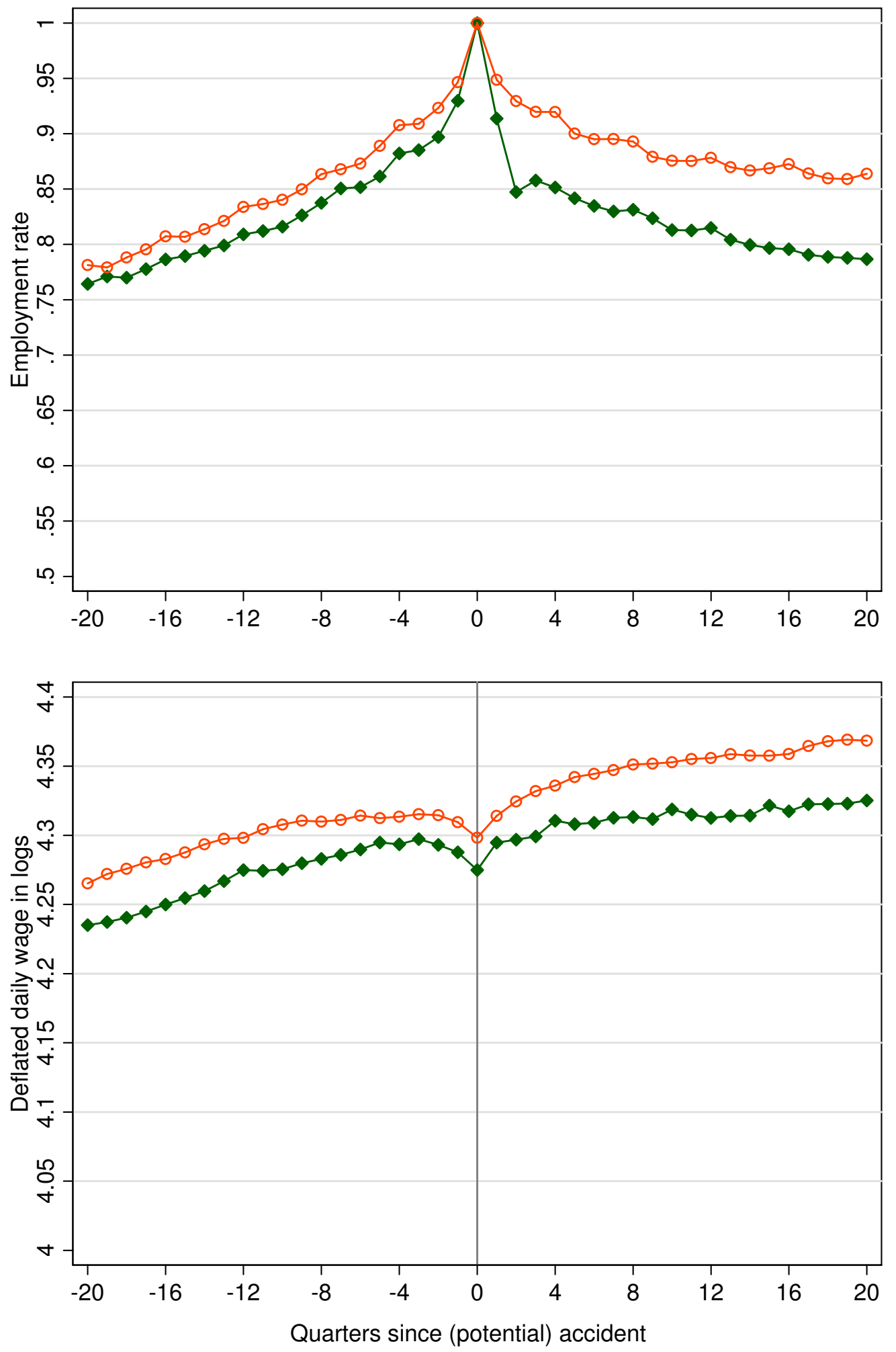

$\longrightarrow$ Treatment group $\longrightarrow$ Control group

${ }^{a}$ These graphs show the employment rate and the average deflated daily log wage (conditional on employment) of all individuals by treatment status. The number of treated individuals is 5,909 , and the number of control individuals is 16,813 . 
Figure 4: The dynamic effect of an accident on sick leave

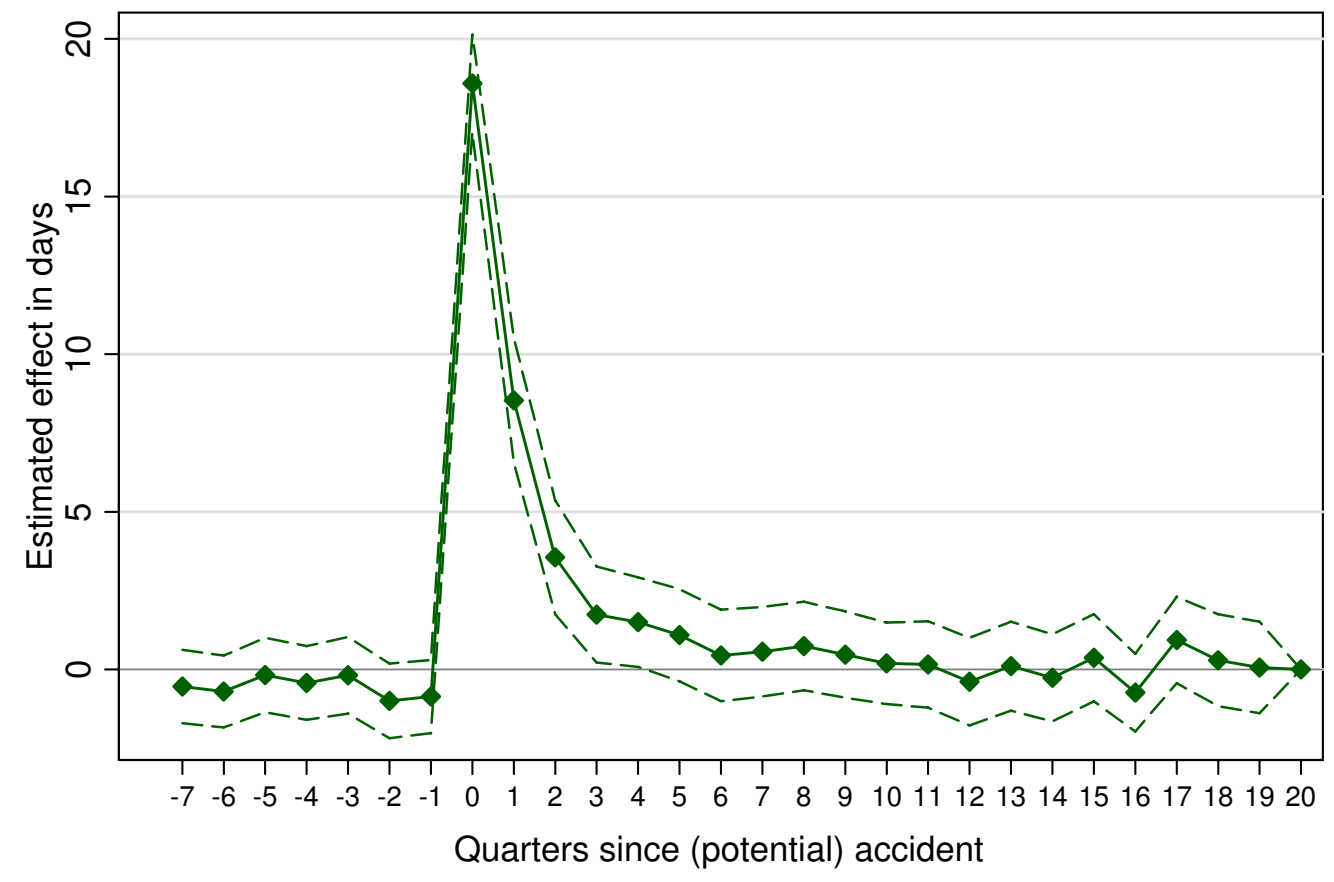

$\sim$ Coef. FE-I ----- $95 \% \mathrm{Cl}$

${ }^{a}$ This graph summarizes estimation results of the effect of a commuting accident on the (prior and) subsequent incidence of sick leave. The dependent variable is equal to the number of days on sick leave per quarter and has an overall sample mean (standard deviation) of 3.8 (9.8). Estimated using a dynamic difference-in-differences approach based on an exactly matched sample of treated and control individuals working in Upper Austria $(N=82,355$ with 616 treated individuals and 2,466 control individuals), where weights account for the fact that treated units may have more than one control subject. The estimation controls for individual, age and quarter fixed effects. The entries give the estimated effect of a commuting accident $r$ quarters ago on the current sick leave (see $\delta^{r}$ in equation 2). The confidence interval (CI) is based on robust standard errors (allowing for clustering by individuals and heteroskedasticity of unknown form). 
Figure 5: The dynamic effect of an accident on employment and earnings (all workers) ${ }^{a}$
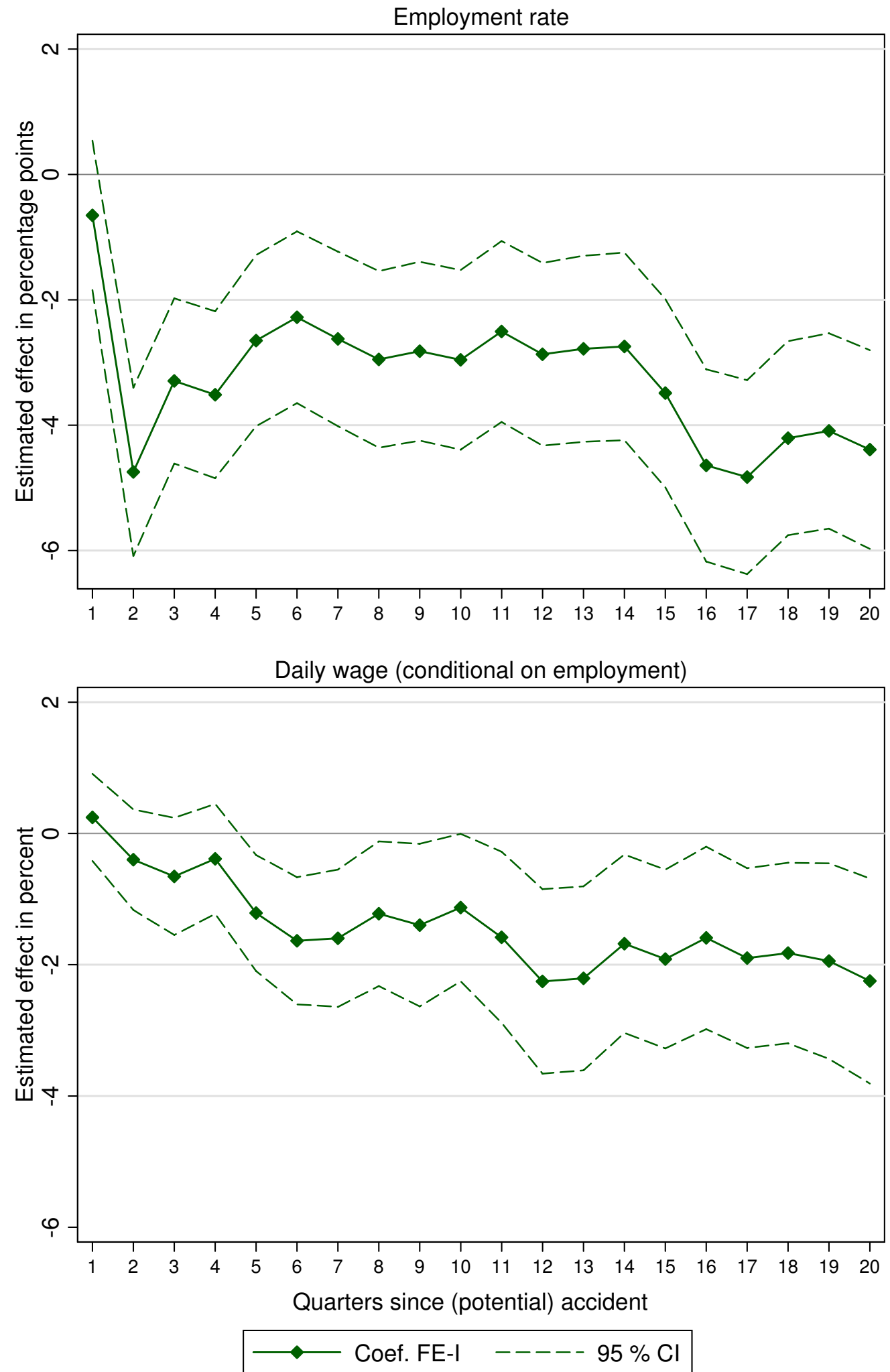

${ }^{a}$ These graphs summarize estimation results of a commuting accident on subsequent employment (upper panel) and the deflated daily log wage conditional on employment (lower panel). Estimated using a dynamic difference-in-differences approach based on an exactly matched sample of treated $(\mathrm{N}=3,406)$ and control individuals $(\mathrm{N}=26,734)$, where weights account for the fact that treated individuals may have more than one control subject. Each estimation includes the same set of control variables as specification FE-I in Table 2. The entries give the estimated effect of a commuting accident $r$ quarters ago on current labor market outcomes (see $\delta^{r}$ in equation 2). The confidence intervals (CI) are based on robust standard errors (allowing for clustering by individuals and heteroskedasticity of unknown form). 
Figure 6: The dynamic effect of an accident on employment (by sex-occupation group) ${ }^{a}$
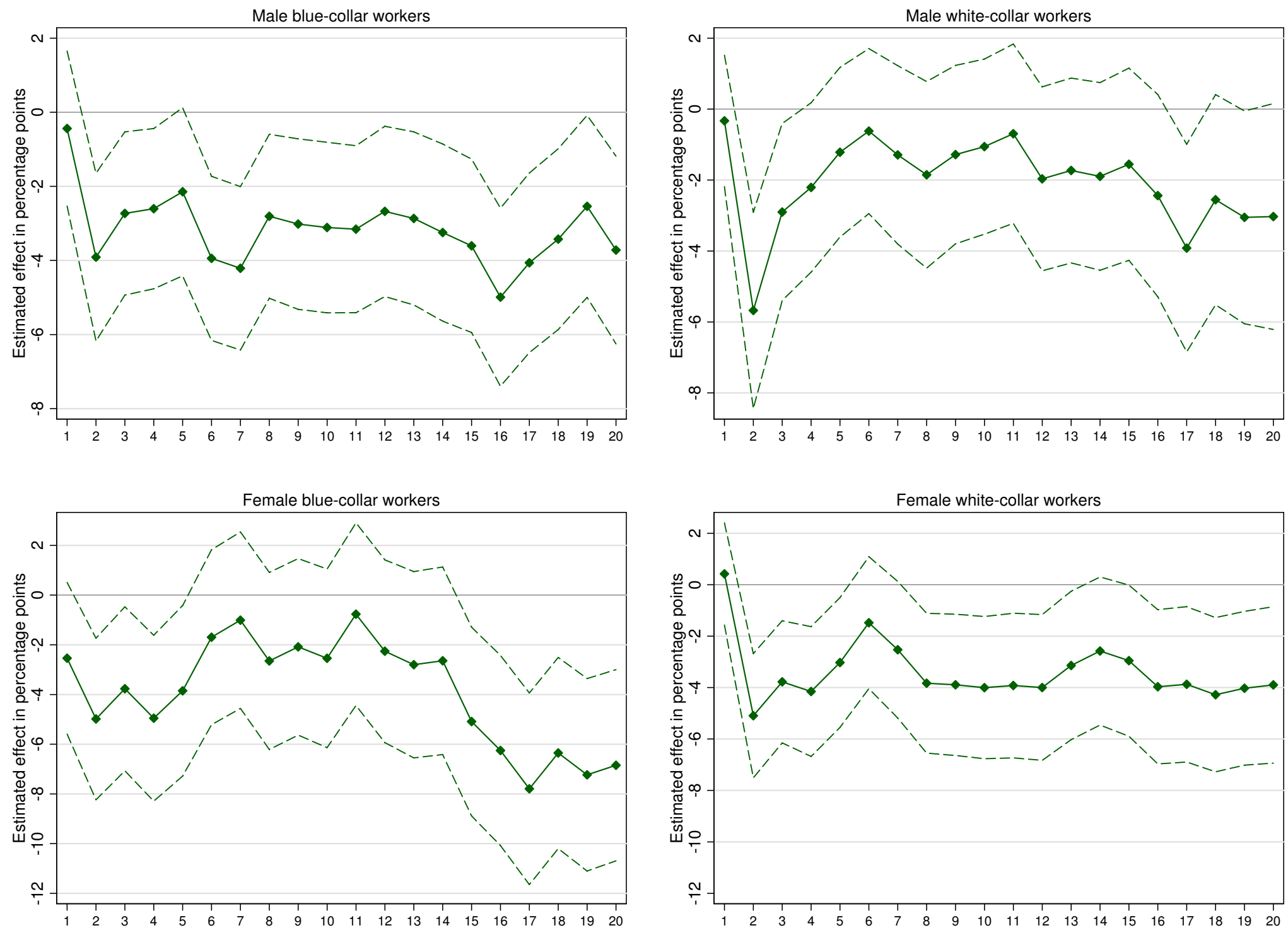

Quarters since (potential) accident

$\longrightarrow$ Coef. FE-I $\quad-----95 \% \mathrm{Cl}$

${ }^{a}$ These graphs summarize estimation results of a commuting accident on subsequent employment for four sub-groups of workers, which are equivalent to the results presented in the upper panel of Figure 5 for the full sample of workers. See, notes to Figure 5 . Male blue-collar workers: $N=1,187$ treated and $N=5,760$ control workers; female blue-collar workers: $N=756$ treated and $N=8,704$ control workers; male blue-collar workers: $N=491$ treated and $N=4,094$ control workers; female blue-collar workers: $N=972$ treated and $N=8,176$ control workers. 
Figure 7: The dynamic effect of an accident on earnings (by sex-occupation group) ${ }^{a}$
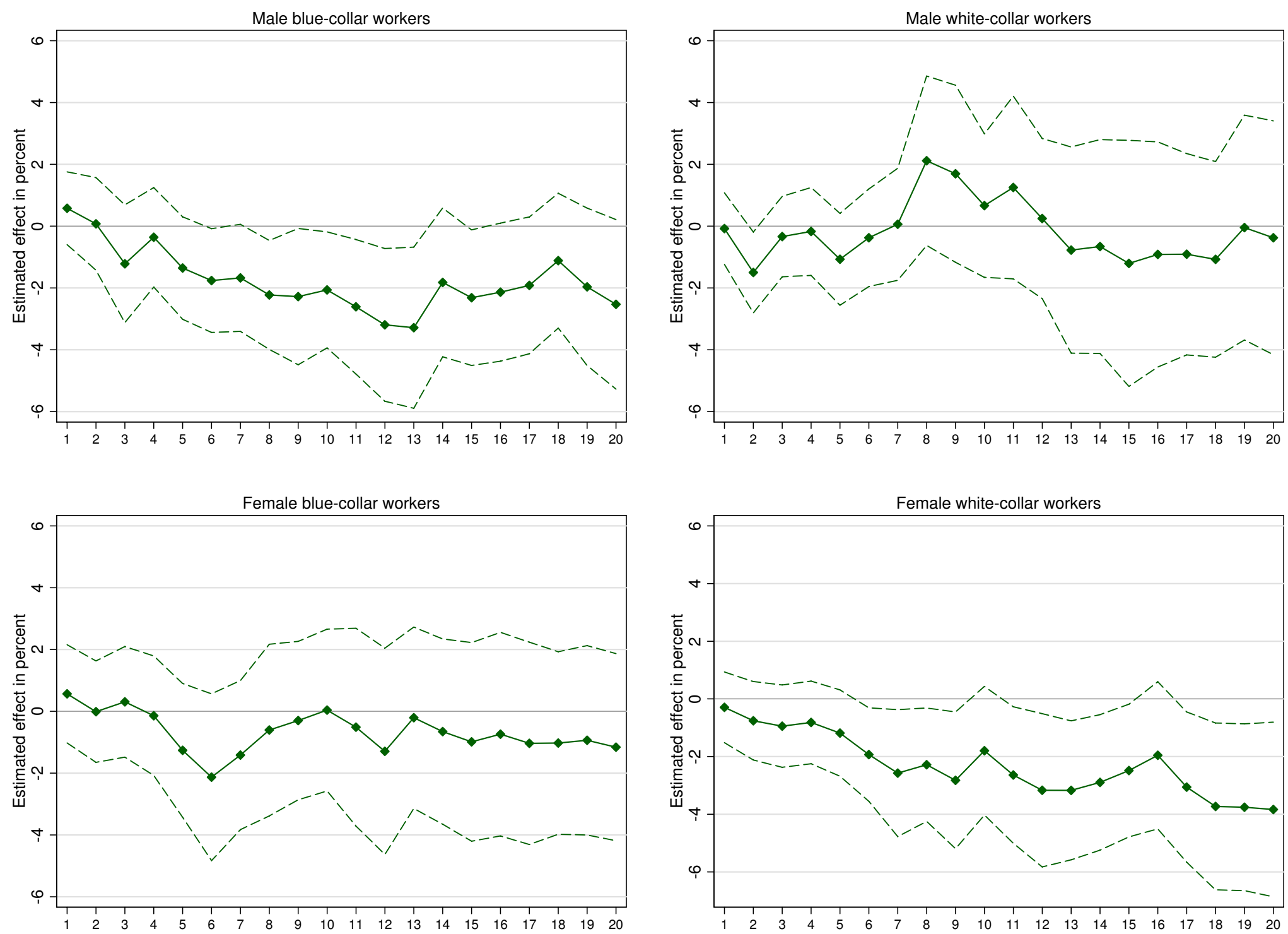

Quarters since (potential) accident

$\longrightarrow$ Coef. FE-I $\quad-----95 \% \mathrm{Cl}$

${ }^{a}$ These graphs summarize estimation results of a commuting accident on the subsequent deflated daily log wage (i. e. conditional on employment) for four sub-groups of workers, which are equivalent to the results presented in the lower panel of Figure 5 for the full sample of workers. See, notes to Figure 5 . Male blue-collar workers: $N=1,187$ treated and $N=5,760$ control workers; female blue-collar workers: $N=756$ treated and $N=8,704$ control workers; male blue-collar workers: $N=491$ treated and $N=4,094$ control workers; female blue-collar workers: $N=972$ treated and $N=8,176$ control workers. 
Figure 8: The dynamic effect of an accident on employment and earnings (by age group) ${ }^{a}$
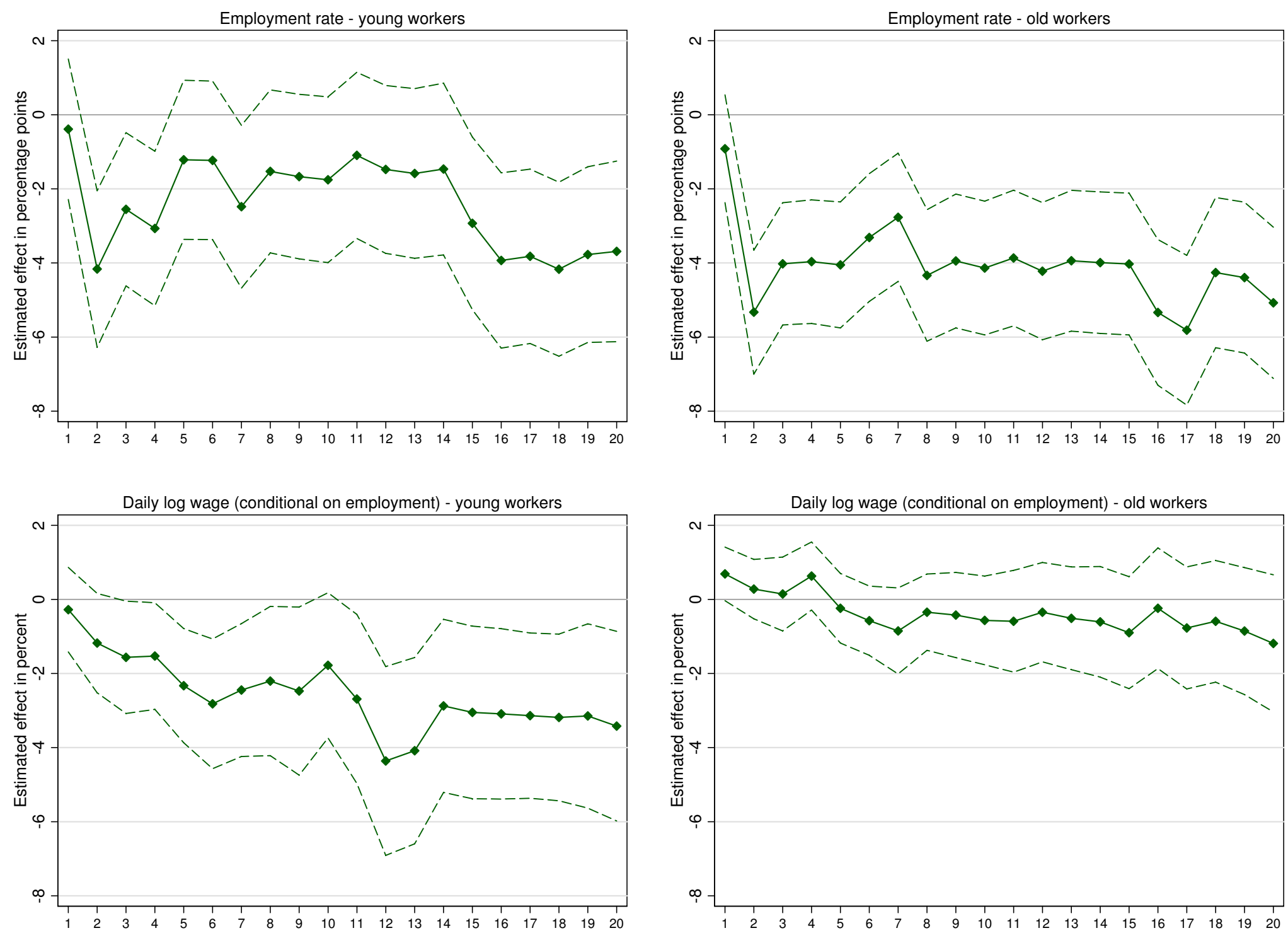

Quarters since (potential) accident

$\longrightarrow$ Coef. FE-I $\quad-----95 \% \mathrm{Cl}$

${ }^{a}$ These graphs summarize estimation results of a commuting accident on subsequent employment (upper panel) and deflated daily log wage conditional on employment (lower panel) for young and old workers separately, which are equivalent to the results presented in Figure 5 for the full sample of workers. Young workers have been below 38 years of age $(N=1,672$ treated and $N=11,576$ control workers $)$ and old workers have been at least 38 years of age $(N=1,734$ workers have been below 38 years of age $(N=1,672$ treated and $N=11,576$ control
treated and 15,158 control workers) at the time of the accident. See notes to Figure 5 . 
Figure 9: Differences in the types of non-employment between the treatment and the control group (by sex-occupation group) ${ }^{a}$
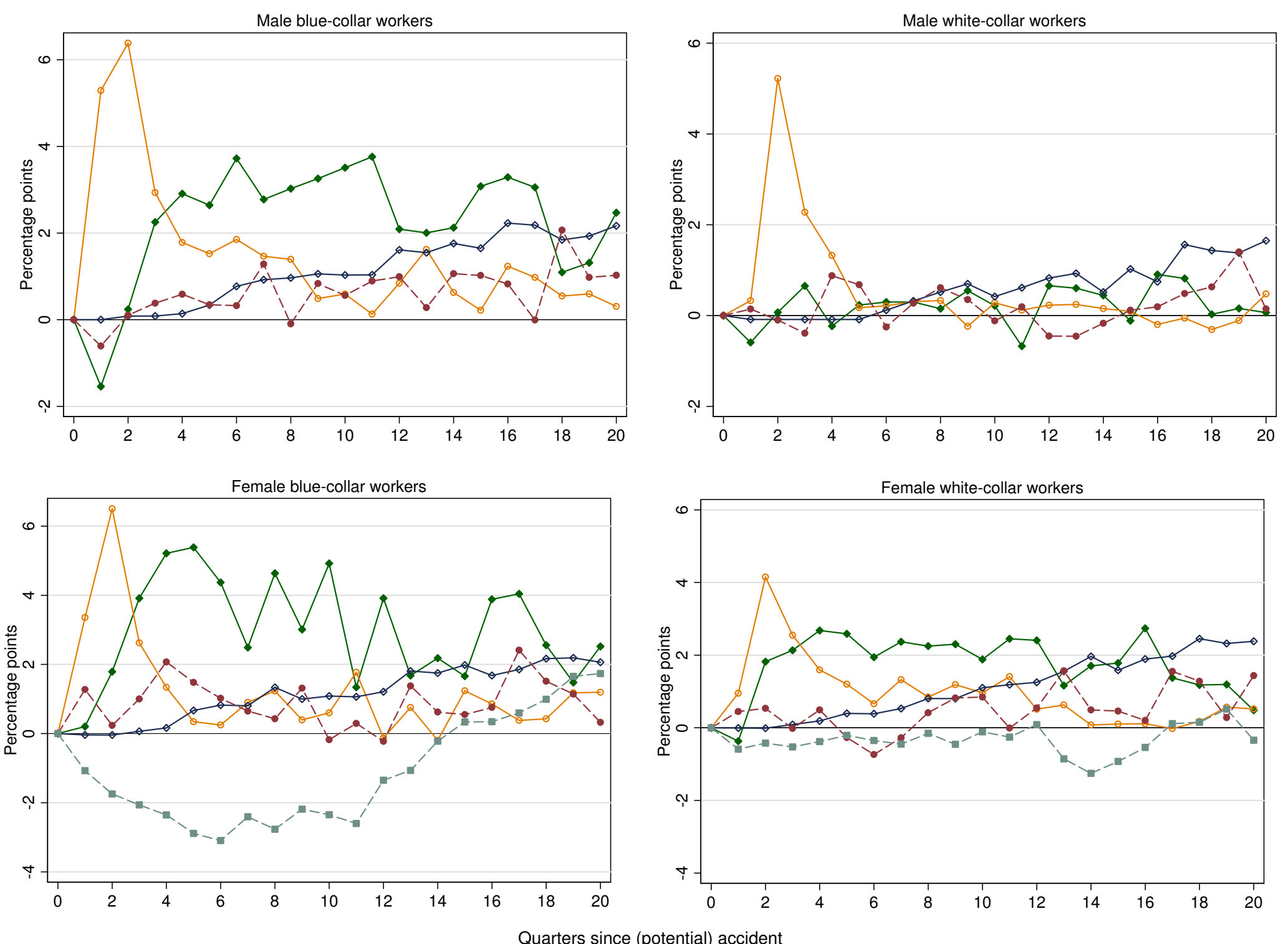

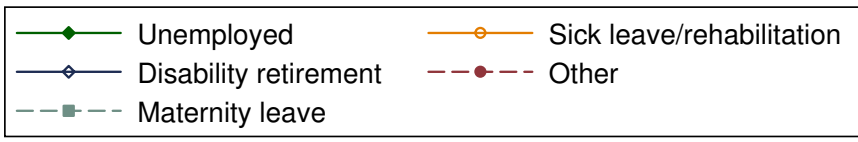

${ }^{a}$ These graphs show the differences in the average rate of different types of non-employment between matched treated and control individuals after the (potential) accident by sex and occupation. 
Figure 10: The dynamic effect of an accident on the subsequent probability to be on maternity leave (female workers by occupation) ${ }^{a}$
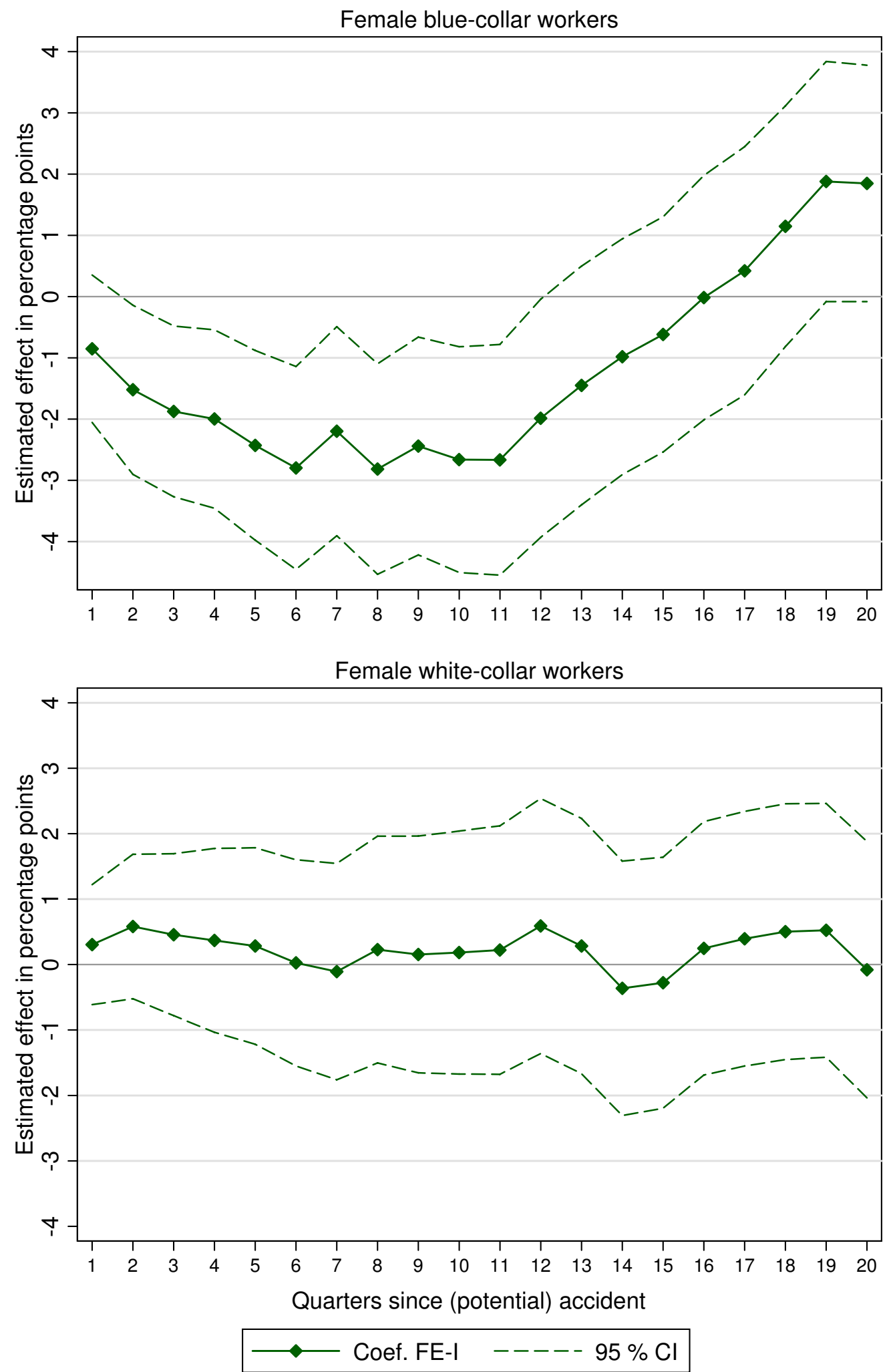

${ }^{a}$ These graphs summarize estimation results of a commuting accident on the subsequent probability to be on maternity leave. Estimated using a dynamic difference-in-differences approach based on an exactly matched sample of treated and control females, where weights account for the fact that treated females may have more than one control subject. Each estimation includes the same set of control variables as specification FE-I in Table 2 and is based on the same number of observations. The entries give the estimated effect of a commuting accident $r$ quarters ago on the current probability of being on maternity leave (see $\delta^{r}$ in equation 2). The confidence intervals (CI) are based on robust standard errors (allowing for clustering by individuals and heteroskedasticity of unknown form). 
Appendix A Additional tables and figures 
Table A.1: Overview of data sources

\begin{tabular}{|c|c|c|}
\hline Database & Coverage & Information (variables) \\
\hline Austrian Worker's Compensation Board (AWCB) & Austria, 2000-2002 & $\begin{array}{l}\text { Information on accidents (date, time, type, days of sick leave, hospitaliza- } \\
\text { tion) }\end{array}$ \\
\hline Austrian Social Security Database (ASSD) & Austria, 1972-2007 & $\begin{array}{l}\text { Basic socio-demographic information (such as age, sex, education and cit- } \\
\text { izenship). Detailed information on labor market status in employment, } \\
\text { unemployment, and various other qualifications (e.g. maternity leave, } \\
\text { disability retirement) on a daily basis. Basic employer information in- } \\
\text { cluding industry classification, firm size and zip-code. For further details, } \\
\text { see, Zweimüller, Winter-Ebmer, Lalive, Kuhn, Wuellrich, Ruf and Büchi } \\
\text { (2009). }\end{array}$ \\
\hline Austrian Federal Ministry of Finance & Austria, 1994-2005 & $\begin{array}{l}\text { From this data source we retrieved information on the place of residence } \\
\text { (zip code) and for } 2002 \text { through } 2005 \text { information on full-time versus part- } \\
\text { time employment. }\end{array}$ \\
\hline Upper Austrian Health Insurance Fund & Upper Austria, 1998-2007 & Days of sick leave, hospitalization, extramural health expenditures. \\
\hline
\end{tabular}


Table A.2: The effect of an accident (with hospitalization) on employment ${ }^{a}$

\begin{tabular}{|c|c|c|}
\hline & OLS & FE-I \\
\hline $\begin{array}{l}\text { ALL WORKERS } \\
(N=354,733)\end{array}$ & $\begin{array}{l}-5.27 \% * * * \\
(1.06)\end{array}$ & $\begin{array}{l}-5.30 \% * * * \\
(1.06)\end{array}$ \\
\hline $\begin{array}{l}\text { MALE WORKERS } \\
(N=150,735)\end{array}$ & $\begin{array}{l}-5.16 \% * * * \\
(1.26)\end{array}$ & $\begin{array}{l}-5.20 \% * * * \\
(1.26)\end{array}$ \\
\hline $\begin{array}{l}\text { FEMALE WORKERS } \\
(N=203,998)\end{array}$ & $\begin{array}{l}-5.37 \% * * * \\
(1.70)\end{array}$ & $\begin{array}{l}-5.39 \% * * * \\
(1.69)\end{array}$ \\
\hline $\begin{array}{l}\text { BLUE-COLLAR WORKERS } \\
(N=169,125)\end{array}$ & $\begin{array}{l}-8.08 \% * * * \\
(1.58)\end{array}$ & $\begin{array}{l}-8.11 \% * * * \\
(1.58)\end{array}$ \\
\hline $\begin{array}{l}\text { WHITE-COLLAR WORKERS } \\
(N=185,608)\end{array}$ & $\begin{array}{l}-2.47 \% * \\
(1.38)\end{array}$ & $\begin{array}{l}-2.49 \% * \\
(1.38)\end{array}$ \\
\hline $\begin{array}{l}\text { MALE BLUE-COLLAR WORKERS } \\
(N=74,895)\end{array}$ & $\begin{array}{l}-7.58 \% * * * \\
(1.70)\end{array}$ & $\begin{array}{l}-7.61 \% * * * \\
(1.70)\end{array}$ \\
\hline $\begin{array}{l}\text { FEMALE BLUE-COLLAR WORKERS } \\
(N=94,230)\end{array}$ & $\begin{array}{l}-8.94 \% * * * \\
(3.19)\end{array}$ & $\begin{array}{l}-8.96 \% * * * \\
(3.17)\end{array}$ \\
\hline $\begin{array}{l}\text { MALE WHITE-COLLAR WORKERS } \\
(N=75,840)\end{array}$ & $\begin{array}{l}-1.13 \% \\
(1.72)\end{array}$ & $\begin{array}{l}-1.19 \% \\
(1.73)\end{array}$ \\
\hline $\begin{array}{l}\text { FEMALE WHITE-COLLAR WORKERS } \\
(N=109,768)\end{array}$ & $\begin{array}{l}-3.28 \% * \\
(1.94)\end{array}$ & $\begin{array}{l}-3.30 \% * \\
(1.94)\end{array}$ \\
\hline $\begin{array}{l}\text { YOUNG WORKERS } \\
(N=152,767)\end{array}$ & $\begin{array}{l}-3.85 \% * * \\
(1.64)\end{array}$ & $\begin{array}{l}-3.88 \% * * \\
(1.64)\end{array}$ \\
\hline $\begin{array}{l}\text { OLD WORKERS } \\
(N=201,966)\end{array}$ & $\begin{array}{l}-6.55 \% * * * \\
(1.35)\end{array}$ & $\begin{array}{l}-6.60 \% * * * \\
(1.35)\end{array}$ \\
\hline Individual fixed effects & No & Yes \\
\hline Age fixed effects & Yes & Yes \\
\hline Quarter fixed effects & Yes & Yes \\
\hline Further covariates (measured at time $\left.t_{0}\right)^{b}$ & Yes & No \\
\hline
\end{tabular}

$\overline{a \text { This table summarizes estimation results of the effect of a commut- }}$ ing accident on subsequent employment (covering twenty quarters after the treatment) stratified by different groups (see lines) and based on two different specifications (see columns), equivalent to those presented in Table 2 in the paper, however, using only treated workers that got hospitalized and their matched control workers. See, notes to Table 2 in the paper. 
Table A.3: The effect of an accident (with hospitalization) on earnings ${ }^{a}$

\begin{tabular}{|c|c|c|c|}
\hline & OLS & FE-I & FE-II \\
\hline $\begin{array}{l}\text { ALL WORKERS } \\
(N=320,044)\end{array}$ & $\begin{array}{l}-0.32 \% \\
(0.81)\end{array}$ & $\begin{array}{l}-1.22 \% * \\
(0.73)\end{array}$ & $\begin{array}{l}-1.44 \% * * \\
(0.70)\end{array}$ \\
\hline $\begin{array}{l}\text { MALE WORKERS } \\
(N=141,499)\end{array}$ & $\begin{array}{l}-1.31 \% \\
(1.03)\end{array}$ & $\begin{array}{l}-1.44 \% \\
(0.97)\end{array}$ & $\begin{array}{l}-1.80 \% * * \\
(0.87)\end{array}$ \\
\hline $\begin{array}{l}\text { FEMALE WORKERS } \\
(N=178,545)\end{array}$ & $\begin{array}{l}0.77 \% \\
(1.25)\end{array}$ & $\begin{array}{l}-1.03 \% \\
(1.10)\end{array}$ & $\begin{array}{l}-1.16 \% \\
(1.11)\end{array}$ \\
\hline $\begin{array}{l}\text { BLUE-COLLAR WORKERS } \\
(N=149,430)\end{array}$ & $\begin{array}{l}-1.20 \% \\
(1.12)\end{array}$ & $\begin{array}{l}-1.95 \% * \\
(1.03)\end{array}$ & $\begin{array}{l}-2.15 \% * * \\
(0.95)\end{array}$ \\
\hline $\begin{array}{l}\text { WHITE-COLLAR WORKERS } \\
(N=170,614)\end{array}$ & $\begin{array}{l}0.30 \% \\
(1.13)\end{array}$ & $\begin{array}{l}-0.65 \% \\
(1.03)\end{array}$ & $\begin{array}{l}-0.85 \% \\
(1.02)\end{array}$ \\
\hline $\begin{array}{l}\text { MALE BLUE-COLLAR WORKERS } \\
(N=69,287)\end{array}$ & $\begin{array}{l}-2.09 \% \\
(1.34)\end{array}$ & $\begin{array}{l}-2.53 \% * * \\
(1.28)\end{array}$ & $\begin{array}{l}-2.60 \% * * \\
(1.08)\end{array}$ \\
\hline $\begin{array}{l}\text { FEMALE BLUE-COLLAR WORKERS } \\
(N=80,143)\end{array}$ & $\begin{array}{l}1.24 \% \\
(2.00)\end{array}$ & $\begin{array}{l}-0.59 \% \\
(1.70)\end{array}$ & $\begin{array}{l}-0.79 \% \\
(1.70)\end{array}$ \\
\hline $\begin{array}{l}\text { MALE WHITE-COLLAR WORKERS } \\
(N=72,212)\end{array}$ & $\begin{array}{l}-0.18 \% \\
(1.51)\end{array}$ & $\begin{array}{l}0.30 \% \\
(1.45)\end{array}$ & $\begin{array}{l}-0.23 \% \\
(1.41)\end{array}$ \\
\hline $\begin{array}{l}\text { FEMALE WHITE-COLLAR WORKERS } \\
(N=98,402)\end{array}$ & $\begin{array}{l}0.34 \% \\
(1.55)\end{array}$ & $\begin{array}{l}-1.27 \% \\
(1.41)\end{array}$ & $\begin{array}{l}-1.21 \% \\
(1.42)\end{array}$ \\
\hline $\begin{array}{l}\text { YOUNG WORKERS } \\
(N=133,035)\end{array}$ & $\begin{array}{l}-2.25 * \% * \\
(1.25)\end{array}$ & $\begin{array}{l}-2.49 \% * * \\
(1.16)\end{array}$ & $\begin{array}{l}-2.67 \% * * \\
(0.66)\end{array}$ \\
\hline $\begin{array}{l}\text { OLD WORKERS } \\
(N=187,009)\end{array}$ & $\begin{array}{l}1.30 \% \\
(1.03)\end{array}$ & $\begin{array}{l}-0.14 \% \\
(0.93)\end{array}$ & $\begin{array}{l}-0.26 \% \\
(0.90)\end{array}$ \\
\hline Individual fixed effects & No & Yes & Yes \\
\hline Age fixed effects & Yes & Yes & Yes \\
\hline Quarter fixed effects & Yes & Yes & Yes \\
\hline Further covariates measured at $t_{0}^{b}$ & Yes & No & No \\
\hline Further covariates measured at $t_{x}{ }^{c}$ & No & No & Yes \\
\hline
\end{tabular}

$\bar{a}$ This table summarizes estimation results of the effect of a commuting accident on the subsequent daily wage rate (covering twenty quarters after the treatment) stratified by different groups (see lines) and based on three different specifications (see columns), equivalent to those presented in Table 3 in the paper, however, using only treated workers that got hospitalized and their matched control workers. See, notes to Table 3 in the paper. 
Table A.4: The effect of an accident on employment (full sample) ${ }^{a}$

\begin{tabular}{|c|c|c|}
\hline & OLS & FE-I \\
\hline $\begin{array}{l}\text { ALL WORKERS } \\
(N=928,602)\end{array}$ & $\begin{array}{l}-4.70 \% * * * \\
(0.43)\end{array}$ & $\begin{array}{l}-4.65 \% * * * \\
(0.43)\end{array}$ \\
\hline $\begin{array}{l}\text { MALE WORKERS } \\
(N=493,685)\end{array}$ & $\begin{array}{l}-5.23 \% * * * \\
(0.51)\end{array}$ & $\begin{array}{l}-5.20 \% * * * \\
(0.50)\end{array}$ \\
\hline $\begin{array}{l}\text { FEMALE WORKERS } \\
(N=434,917)\end{array}$ & $\begin{array}{l}-4.28 \% * * * \\
(0.70)\end{array}$ & $\begin{array}{l}-4.24 \% * * * \\
(0.70)\end{array}$ \\
\hline $\begin{array}{l}\text { BLUE-COLLAR WORKERS } \\
(N=452,209)\end{array}$ & $\begin{array}{l}-4.49 \% * * * \\
(0.58)\end{array}$ & $\begin{array}{l}-4.42 \% * * * \\
(0.57)\end{array}$ \\
\hline $\begin{array}{l}\text { WHITE-COLLAR WORKERS } \\
(N=476,393)\end{array}$ & $\begin{array}{l}-4.28 \% * * * \\
(0.64)\end{array}$ & $\begin{array}{l}-4.28 \% * * * \\
(0.64)\end{array}$ \\
\hline $\begin{array}{l}\text { MALE BLUE-COLLAR WORKERS } \\
(N=297,186)\end{array}$ & $\begin{array}{l}-4.91 \% * * * \\
(0.62)\end{array}$ & $\begin{array}{l}-4.87 \% * * * \\
(0.62)\end{array}$ \\
\hline $\begin{array}{l}\text { FEMALE BLUE-COLLAR WORKERS } \\
(N=155,023)\end{array}$ & $\begin{array}{l}-4.22 \% * * * \\
(1.15)\end{array}$ & $\begin{array}{l}-4.19 \% * * * \\
(1.15)\end{array}$ \\
\hline $\begin{array}{l}\text { MALE WHITE-COLLAR WORKERS } \\
(N=196,499)\end{array}$ & $\begin{array}{l}-4.20 \% * * * \\
(0.86)\end{array}$ & $\begin{array}{l}-4.21 \% * * * \\
(0.86)\end{array}$ \\
\hline $\begin{array}{l}\text { FEMALE WHITE-COLLAR WORKERS } \\
(N=279,894)\end{array}$ & $\begin{array}{l}-4.56 \% * * * \\
(0.88)\end{array}$ & $\begin{array}{l}-4.56 \% * * * \\
(0.88)\end{array}$ \\
\hline $\begin{array}{l}\text { YOUNG WORKERS } \\
(N=490,478)\end{array}$ & $\begin{array}{l}-4.04 \% * * * \\
(0.62)\end{array}$ & $\begin{array}{l}-4.06 \% \text { *** } \\
(0.62)\end{array}$ \\
\hline $\begin{array}{l}\text { OLD WORKERS } \\
(N=438,124)\end{array}$ & $\begin{array}{l}-5.28 \% * * * \\
(0.58)\end{array}$ & $\begin{array}{l}-5.23 \% * * * \\
(0.58)\end{array}$ \\
\hline Individual fixed effects & No & Yes \\
\hline Age fixed effects & Yes & Yes \\
\hline Quarter fixed effects & Yes & Yes \\
\hline Further covariates (measured at time $t_{0}$ ) & Yes & No \\
\hline
\end{tabular}

$\bar{a}$ This table summarizes estimation results of the effect of a commuting accident on subsequent employment (covering twenty quarters after the treatment) stratified by different groups (see lines) and based on two different specifications (see columns), equivalent to those presented in Table 2 in the paper, however, using the full set of available treated individuals and a $1 \%$ random sample of control units. See, notes to Table 2 in the paper. 
Table A.5: The effect of an accident on earnings (full sample) ${ }^{a}$

\begin{tabular}{|c|c|c|c|}
\hline & OLS & FE-I & FE-II \\
\hline $\begin{array}{l}\text { ALL WORKERS } \\
(N=797,614)\end{array}$ & $\begin{array}{l}-1.25 \% * * * \\
(0.42)\end{array}$ & $\begin{array}{l}-2.03 \% * * * \\
(0.39)\end{array}$ & $\begin{array}{l}-2.31 \% \text { *** } \\
(0.34)\end{array}$ \\
\hline $\begin{array}{l}\text { MALE WORKERS } \\
(N=437,737)\end{array}$ & $\begin{array}{l}-1.35 \% * * \\
(0.54)\end{array}$ & $\begin{array}{l}-1.94 \% * * * \\
(0.52)\end{array}$ & $\begin{array}{l}-2.37 \% * * * \\
(0.43)\end{array}$ \\
\hline $\begin{array}{l}\text { FEMALE WORKERS } \\
(N=359,877)\end{array}$ & $\begin{array}{l}-1.57 \% * * \\
(0.65)\end{array}$ & $\begin{array}{l}-2.40 \% * * * \\
(0.59)\end{array}$ & $\begin{array}{l}-2.45 \% * * * \\
(0.54)\end{array}$ \\
\hline $\begin{array}{l}\text { BLUE-COLLAR WORKERS } \\
(N=378,966)\end{array}$ & $\begin{array}{l}-0.03 \% \\
(0.54)\end{array}$ & $\begin{array}{l}-0.70 \% \\
(0.52)\end{array}$ & $\begin{array}{l}-0.71 \% \\
(0.44)\end{array}$ \\
\hline $\begin{array}{l}\text { WHITE-COLLAR WORKERS } \\
(N=418,648)\end{array}$ & $\begin{array}{l}-1.65 \% * * \\
(0.65)\end{array}$ & $\begin{array}{l}-2.27 \% * * * \\
(0.60)\end{array}$ & $\begin{array}{l}-2.73 \% \text { *** } \\
(0.53)\end{array}$ \\
\hline $\begin{array}{l}\text { MALE BLUE-COLLAR WORKERS } \\
(N=256,804)\end{array}$ & $\begin{array}{l}-0.69 \% \\
(0.65)\end{array}$ & $\begin{array}{l}-1.09 \% * \\
(0.63)\end{array}$ & $\begin{array}{l}-1.05 \% * * \\
(0.51)\end{array}$ \\
\hline $\begin{array}{l}\text { FEMALE BLUE-COLLAR WORKERS } \\
(N=122,162)\end{array}$ & $\begin{array}{l}-0.70 \% \\
(0.98)\end{array}$ & $\begin{array}{l}-0.31 \% \\
(0.90)\end{array}$ & $\begin{array}{l}-0.28 \% \\
(0.84)\end{array}$ \\
\hline $\begin{array}{l}\text { MALE WHITE-COLLAR WORKERS } \\
(N=180,933)\end{array}$ & $\begin{array}{l}-0.61 \% \\
(0.95)\end{array}$ & $\begin{array}{l}-1.41 \% \\
(0.89)\end{array}$ & $\begin{array}{l}-2.29 \% * * * \\
(0.75)\end{array}$ \\
\hline $\begin{array}{l}\text { FEMALE WHITE-COLLAR WORKERS } \\
(N=237,715)\end{array}$ & $\begin{array}{l}-2.63 \% * * * \\
(0.86)\end{array}$ & $\begin{array}{l}-3.12 \% * * * \\
(0.79)\end{array}$ & $\begin{array}{l}-3.14 \% \text { *** } \\
(0.71)\end{array}$ \\
\hline $\begin{array}{l}\text { YOUNG WORKERS } \\
(N=407,478)\end{array}$ & $\begin{array}{l}-0.67 \% \\
(0.2 .56)\end{array}$ & $\begin{array}{l}-3.52 \% * * * \\
(0.63)\end{array}$ & $\begin{array}{l}-3.64 \% * * * \\
(0.54)\end{array}$ \\
\hline $\begin{array}{l}\text { OLD WORKERS } \\
(N=390,136)\end{array}$ & $\begin{array}{l}-0.22 \% \\
(0.51)\end{array}$ & $\begin{array}{l}-0.51 \% \\
(0.47)\end{array}$ & $\begin{array}{l}-0.97 \% * * \\
(0.42)\end{array}$ \\
\hline Individual fixed effects & No & Yes & Yes \\
\hline Age fixed effects & Yes & Yes & Yes \\
\hline Quarter fixed effects & Yes & Yes & Yes \\
\hline Further controls (measured at $t_{0}$ ) & Yes & No & No \\
\hline Further controls (measured at $t_{x}$ ) & No & No & Yes \\
\hline
\end{tabular}

$a$ This table summarizes estimation results of the effect of a commuting accident on the subsequent daily wage rate, equivalent to those presented in Table 3 in the paper, however, using the full set of available treated individuals and a $1 \%$ random sample of control units. See, notes to Table 3 in the paper. 
Figure A.1: Pre- and post treatment employment and earnings differences ${ }^{a}$
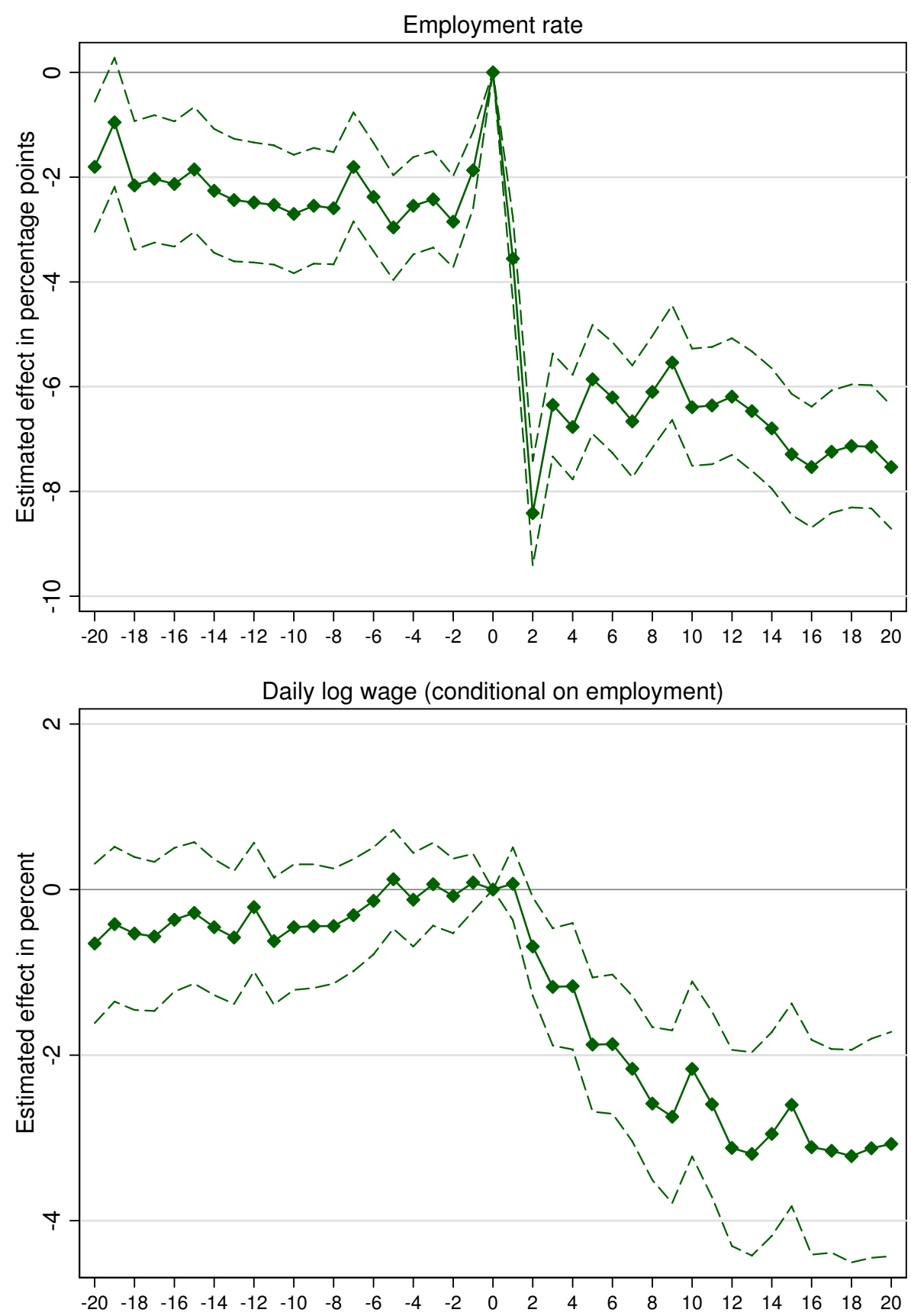

${ }^{a}$ These graphs shows differences in the pre- and post treatment employment (upper panel) and earnings (lower panel) between treated units (green line) and control units (base group) based on estimations that control for leads up to minus twenty quarters before, lags up to twenty quarters after the (potential) accident, absolute (calendar) time-fixed effects (consecutive quarter dummies), age-fixed effects, and individual fixed/effects. 
Figure A.2: Employment rate and earnings by treatment status (matched sample) ${ }^{a}$
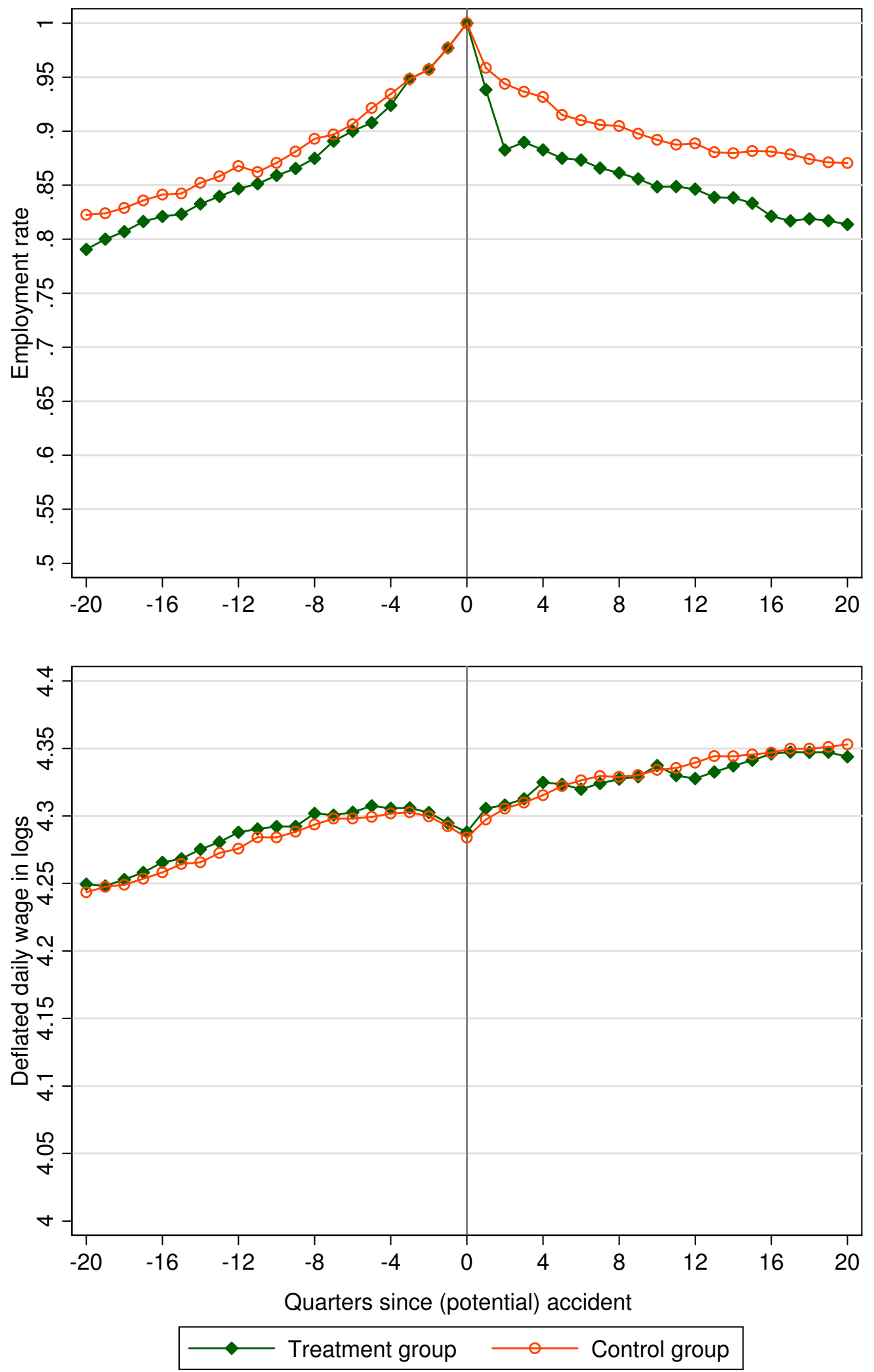

${ }^{a}$ These graphs show the employment rate and the average deflated daily log wage (conditional on employment) of all individuals by treatment status in the matched sample. The number of treated individuals is 3,406 , and the number of control individuals is 26,734 . 
Figure A.3: The effect of an accident on the likelihood of working part-time ${ }^{a}$
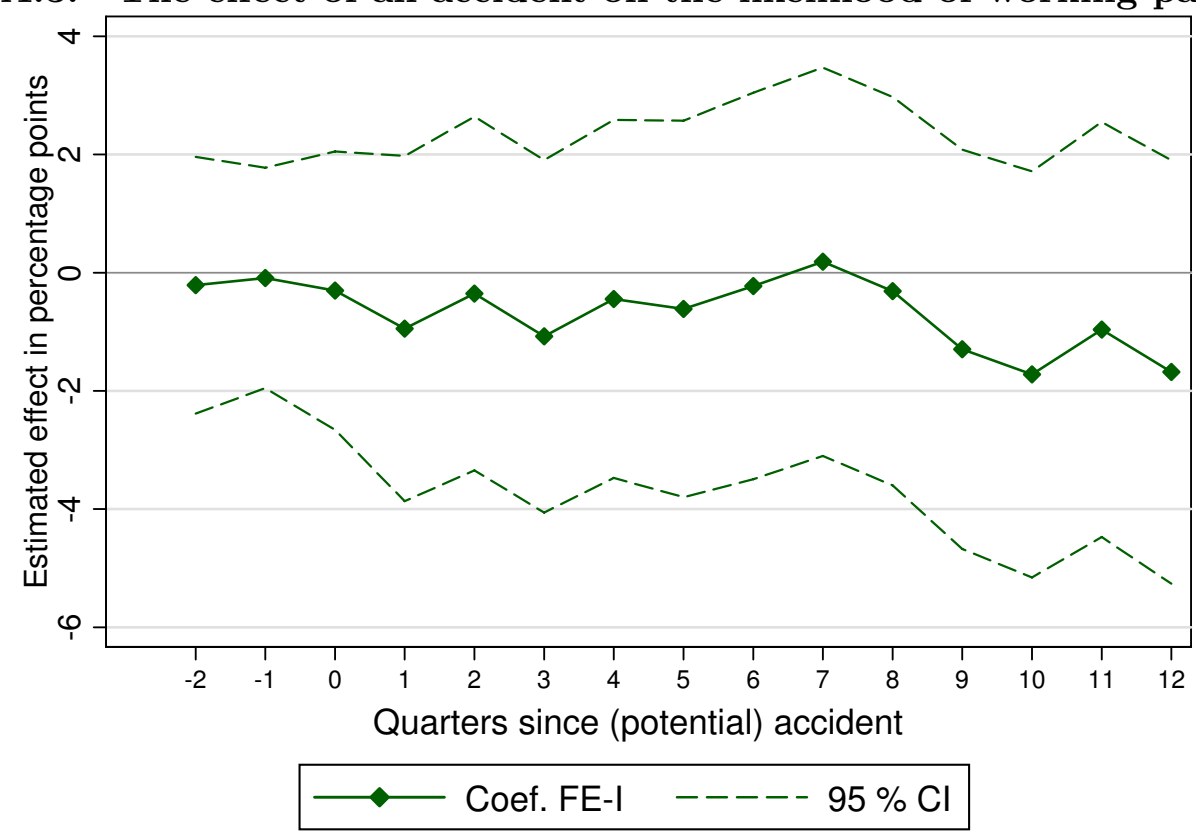

${ }^{a}$ This graph summarizes estimation results of the effect of a commuting accident on the (prior and) subsequent likelihood to work part-time. The dependent variable is equal to one if the worker is part-time employed on the first day of the quarter, and zero if the worker has a full-time employment. Estimated using a dynamic difference-indifferences approach based on an exactly matched sample of treated $(\mathrm{N}=1,048)$ and control $(\mathrm{N}=8,473)$ individuals covering the period from 2002 through 2005, where weights account for the fact that treated individuals may have more than one control subject. The estimation controls for individual, age and quarter fixed effects. The entries give the estimated effect of a commuting accident $r$ quarters ago on the current likelihood of part-time employment (see $\delta^{r}$ in equation 2). The confidence interval (CI) is based on robust standard errors (allowing for clustering by individuals and heteroskedasticity of unknown form). 


\section{Appendix B Health outcomes}

In this section we provide further results from our supplementary analysis of the effect of a commuting accident on (prior and) subsequent health outcomes. Since we observe health outcomes only for workers in Upper Austria, we have to restrict our sample to the 620 treated and 2, 482 matched control individuals working there. ${ }^{1}$ In particular, we have access to the database of the Upper Austrian Health Insurance Fund, which covers basically all private-sector employees of Upper Austria. This data includes individual records from 1998 through 2007 with all covered health services that have been provided to a worker by general practitioners (or resident medical specialists). That means, we can observe each single doctor visit and each drug that has been prescribed, with the exact date of service utilization. Moreover, the database includes exact information on sick leave spells and days of hospitalization.

In order to examine the effect of the commuting accident on health we use the following outcomes (each measured per quarter): (i) days of sick leave, (ii) days of hospitalization, and (iii) extramural health expenditures. For each outcome variable we estimate a dynamic model as described by equation (2), where we in addition include leads starting at quarter minus 7 . For the incidence of hospitalization and extramural health expenditures (see Figure B.1 below) we observe patterns, very similar to those of sick leave (as discussed in Section 4 of the paper; see Figure 4). In the case of all three outcomes we find that the coefficients capturing the seven quarters prior to the accident are de facto zero and do not exhibit any trend. (The base group is equal to quarter minus eight.) In the quarter of the accident we observe a huge spike, indicating that treated workers experience a severe negative health shock: plus 18.6 days of sick leave, plus 2 days in hospital, and plus Euro 47.8 higher health expenditures. ${ }^{2}$ The timing clearly suggests that the commuting accident (and not any other unobserved time-invariant factor) is the causal trigger of this negative health shock. After the quarter of the treatment, the negative health effect decrease and dissipate over time. The estimated effects of the accident on health outcomes are perfectly in line with the observed dynamic effects on employment and earnings.

\footnotetext{
${ }^{1}$ Upper Austria is one of the nine states of Austria and comprises about one sixth of the Austrian population and work force.

${ }^{2}$ Given mean values of $3.8,0.3$, and 88.2 , this is equal to a 490 percent increase in sick leave, a 667 percent increase in hospital days, and 54 percent increase in health expenditures.
} 
Figure B.1: The effect of an accident on hospitalization and extramural health expenditures $^{a}$
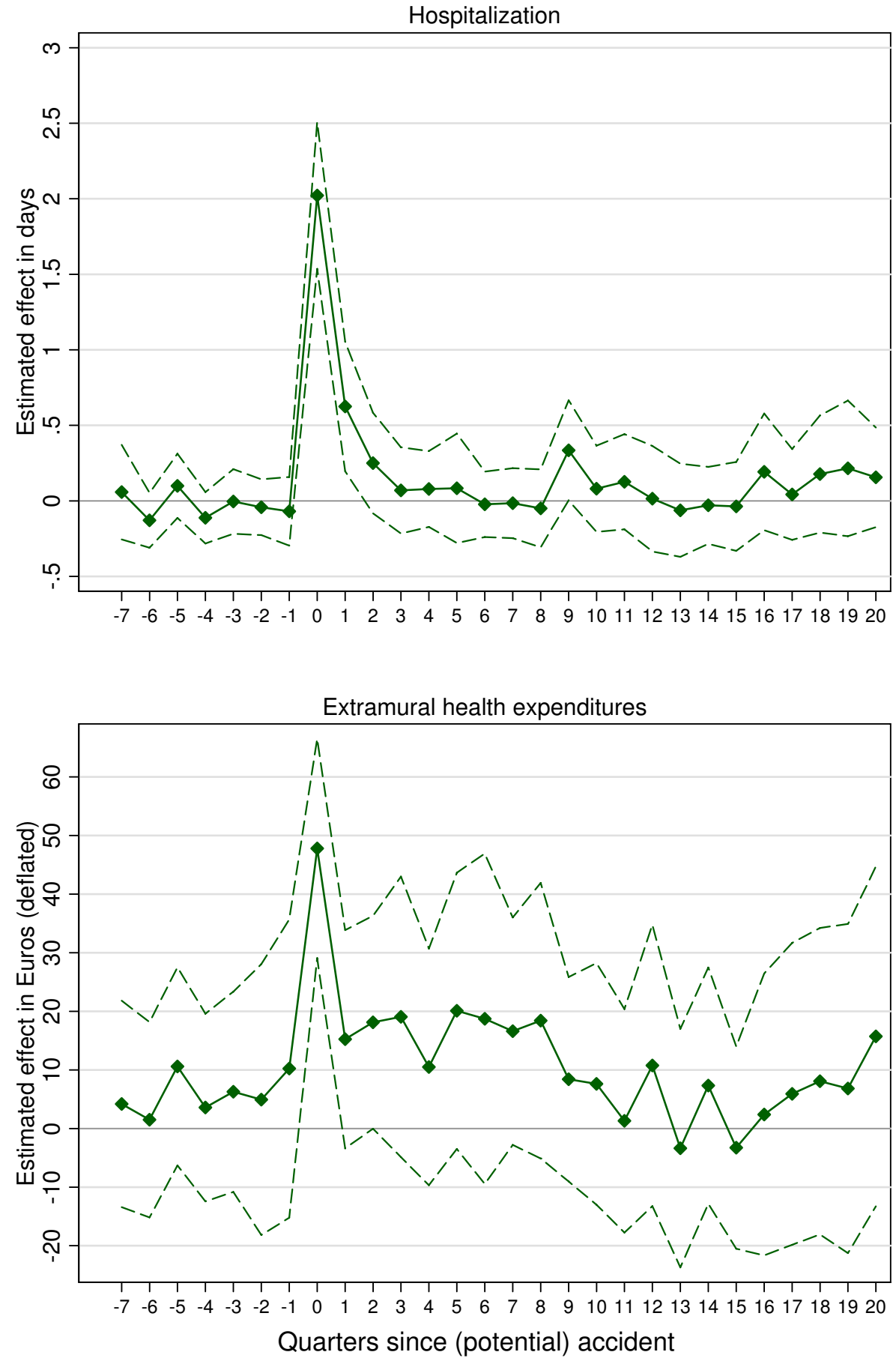

Coef. FE-I $\quad-----95 \% \mathrm{Cl}$

\begin{abstract}
${ }^{a}$ These graphs summarizes estimation results of the effect of a commuting accident on the (prior and) subsequent hospitalization and extramural health expenditures. In the upper panel the dependent variable is equal to the number of days spent in hospital; this has an overall sample mean (standard deviation) of 0.3 (2.3). In the lower panel the dependent variable is equal to extramural health expenditures in constant Euros; this has an overall sample mean (standard deviation) of 88.2 (209.2). Estimated using a dynamic difference-in-differences approach based on an exactly matched sample of treated and control individuals working in Upper Austria $(N=89,822$ with 620 treated individuals and 2, 482 control individuals), where weights account for the fact that treated individuals may have more than one control subject. The estimation controls for individual, age and quarter fixed effects. The entries give the estimated effect of a commuting accident $r$ quarters ago on the current sick leave (see $\delta^{r}$ in equation 2 ). The confidence intervals (CI) are based on robust standard errors (allowing for clustering by individuals and heteroskedasticity of unknown form).
\end{abstract}




\section{Appendix C Less severe accidents}

In this section we present the estimated effects of less severe commuting accidents. That means, we focus on the 5, 488 treated individuals with accidents causing less than two weeks of sick leave. After applying an equivalent matching procedure as above we have 3,323 matched treated and 27,349 matched controls for our estimation analysis available (i.e. 61 percent matching rate). The average sick leave spell in the sample of matched treated is equal to 7.6 days with a standard deviation of 3.4 days. Given the reduced accident severity we clearly expect smaller effects on subsequent labor market outcomes compared to our main analysis of more severe accidents (i. e. at least two weeks of sick leave) from above. Table C.1 summarizes the estimation results from the static model for subsequent employment and earnings. These estimates can be compared with the results on more severe accident listed in the second column in Table 2 in the paper and with the second column in Table 3 in the paper. We see that less severe commuting accidents have smaller (or no) effects on employment. The estimated effects on earnings (conditional on employment) are also considerably smaller and statistically insignificant throughout. Since it seems highly unlikely that less and more severe commuting accidents are consistently correlated with unobserved time-variant confounding factors that have small and large effects on labor market outcomes, this analysis strongly supports our causal interpretation from above. 
Table C.1: The effect of less severe accidents on employment and earnings ${ }^{a}$

\begin{tabular}{|c|c|c|}
\hline & EMPLOYMENT & EARNINGS $^{b}$ \\
\hline $\begin{array}{l}\text { ALL WORKERS } \\
(N=1.253,518)\end{array}$ & $\begin{array}{l}-0.49 \% \\
(0.53)\end{array}$ & $\begin{array}{l}-0.10 \% \\
(0.46)\end{array}$ \\
\hline $\begin{array}{l}\text { MALE WORKERS } \\
(N=437,768)\end{array}$ & $\begin{array}{l}-1.22 \% * * \\
(0.62)\end{array}$ & $\begin{array}{l}-0.25 \% \\
(0.69)\end{array}$ \\
\hline $\begin{array}{l}\text { FEMALE WORKERS } \\
(N=815,750)\end{array}$ & $\begin{array}{l}0.15 \% \\
(0.83)\end{array}$ & $\begin{array}{l}0.03 \% \\
(0.61)\end{array}$ \\
\hline $\begin{array}{l}\text { BLUE-COLLAR WORKERS } \\
(N=626,550)\end{array}$ & $\begin{array}{l}-1.23 \% * \\
(0.73)\end{array}$ & $\begin{array}{l}-0.44 \% \\
(0.64)\end{array}$ \\
\hline $\begin{array}{l}\text { WHITE-COLLAR WORKERS } \\
(N=626,968)\end{array}$ & $\begin{array}{l}0.26 \% \\
(0.77)\end{array}$ & $\begin{array}{l}0.18 \% \\
(0.67)\end{array}$ \\
\hline $\begin{array}{l}\text { MALE BLUE-COLLAR WORKERS } \\
(N=236,610)\end{array}$ & $\begin{array}{l}-0.91 \% \\
(0.78)\end{array}$ & $\begin{array}{l}-0.38 \% \\
(0.84)\end{array}$ \\
\hline $\begin{array}{l}\text { FEMALE BLUE-COLLAR WORKERS } \\
(N=389,940)\end{array}$ & $\begin{array}{l}-1.69 \% \\
(1.39)\end{array}$ & $\begin{array}{l}-0.52 \% \\
(0.96)\end{array}$ \\
\hline $\begin{array}{l}\text { MALE WHITE-COLLAR WORKERS } \\
(N=201,158)\end{array}$ & $\begin{array}{l}-1.74 \% * \\
(0.98)\end{array}$ & $\begin{array}{l}-0.03 \% \\
(1.19)\end{array}$ \\
\hline $\begin{array}{l}\text { FEMALE WHITE-COLLAR WORKERS } \\
(N=425,810)\end{array}$ & $\begin{array}{l}1.31 \% \\
(1.04)\end{array}$ & $\begin{array}{l}0.34 \% \\
(0.79)\end{array}$ \\
\hline $\begin{array}{l}\text { YOUNG WORKERS } \\
(N=591,315)\end{array}$ & $\begin{array}{l}0.45 \% \\
(0.77)\end{array}$ & $\begin{array}{l}-0.16 \% \\
(0.63)\end{array}$ \\
\hline $\begin{array}{l}\text { OLD WORKERS } \\
(N=662,203)\end{array}$ & $\begin{array}{l}-1.67 \% * * \\
(0.71)\end{array}$ & $\begin{array}{l}-0.04 \% \\
(0.67)\end{array}$ \\
\hline Individual fixed effects & Yes & Yes \\
\hline Age fixed effects & Yes & Yes \\
\hline Quarter fixed effects & Yes & Yes \\
\hline
\end{tabular}

$\bar{a}$ This table summarizes estimation results of the effect of a commuting accident on subsequent employment and earnings, equivalent to those presented in the second columns of Table 2 and Table 3 in the paper, however using less severe accidents (i. e. those with less than two weeks of sick leave). See, notes to Table 2 and Table 3 in the paper. ${ }^{b}$ The earnings regressions are based on employed individuals only; thus, the number of observations is lower than indicated in the first column of the table. 


\section{Appendix D Weather conditions}

In this section we summarize our estimation results on the effect of weather conditions on the likelihood of a commuting accident in the full sample. The purpose of this supplementary analysis is twofold. First, we take weather as an example for a clear exogenous factor that affects the likelihood of a commuting accident to support the idea that these accidents are caused by exogenous events. Second, this analysis complements the descriptive statistics discussed in Section 2 by giving the ceteris paribus effects of different socio-economic characteristics on the likelihood of having a commuting accident.

To measure weather conditions on a worker's way to and from work, we bisect the linear distance between work and place of residence (i.e. in both cases we assume the center of the zip-code area), and assign the closest weather station. Weather data is provided by the Central Institute for Meteorology and Geodynamics - the national meteorological and geophysical service of Austria. Data is collected based on 121 semi-automatic weather stations, which provide a set of meteorological parameters (such as temperature, precipitation, relative humidity, barometric pressure, sunshine etc.) on a hourly base. The average distance between the weather stations and the mid-point between work and place of residence is about 8.3 kilometers (the standard deviation is equal to 7.2 kilometers).

In the case of treated individuals, we look at the weather on the day of the commuting accident (i.e. simple average of weather conditions between 5 am and $7 \mathrm{pm}$ ). For control individuals we have randomly assigned a date from the treatment period. To define bad weather conditions we compare different indicators measured at a weather station on a certain date (during the treatment period) with the corresponding historical average (based on data from 1990 through 1999) from that particular calendar day. For instance, we define a day as 'wet' if the precipitation on this day is above average precipitation on this calendar day from 1990 to 1999. A linear probability model of the likelihood of having a commuting accident including a binary variable indicating such a wet day is summarized for female and male workers in Table D.1 below. Further covariates are the commuting distance, month fixed effects, weekday fixed effects, region of residence fixed effects (NUTS 3), place of work fixed effects (states), industry fixed effects, weather station fixed effects, and a set of socio-economic variables. Based on this simple specification we find that on days with an above average precipitation (i.e. compared to historical average at this specific location on this specific calendar day) the likelihood of an accident increases for women (men) by 4.4 (2.0) percentage points. Clearly, these estimates are just lower bound estimates, since we can measure the weather conditions on a worker's way to and from work only with error. 
Table D.1: Determinants of a commuting accident (full sample) ${ }^{a}$

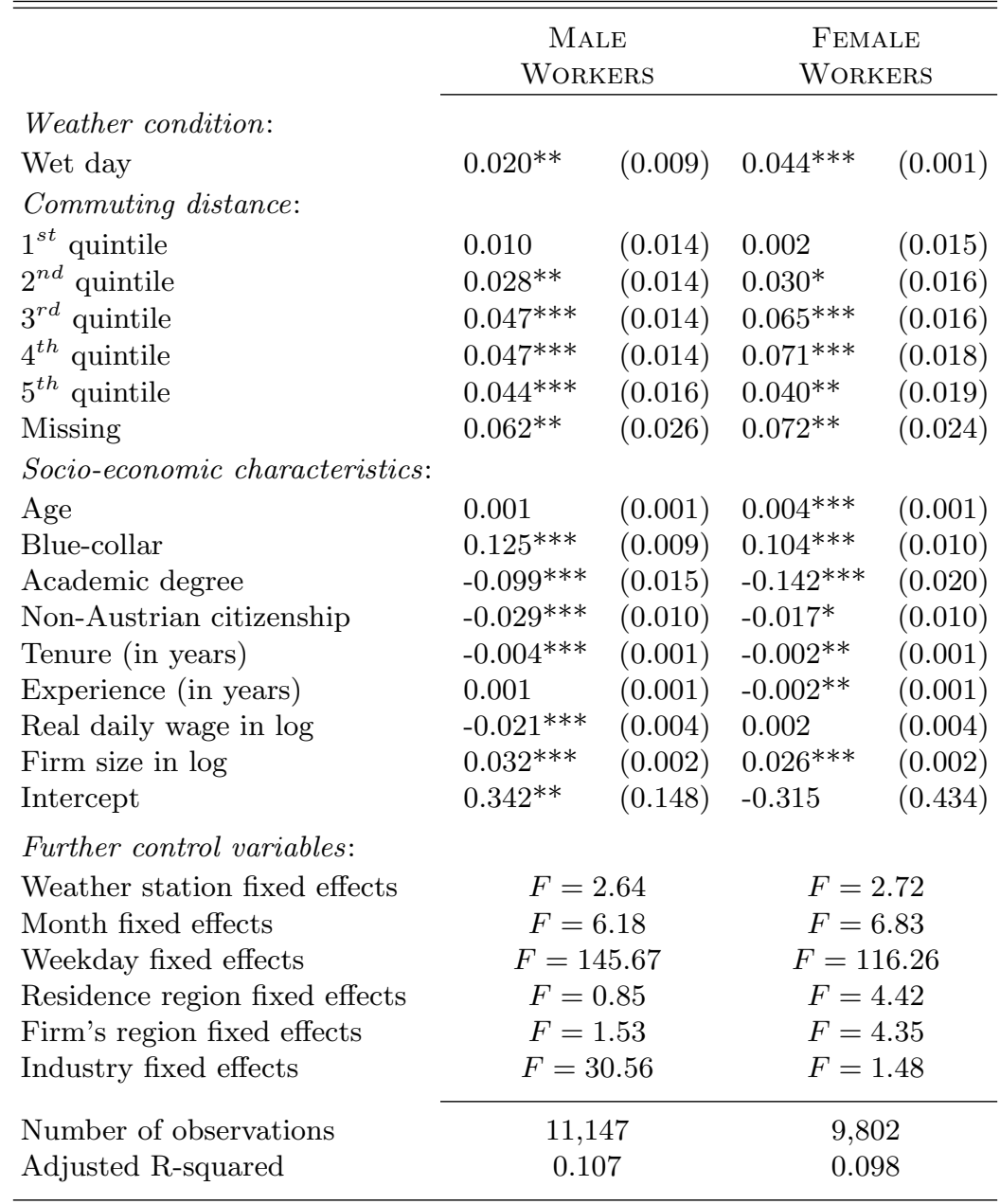

${ }^{a}$ Robust standard errors (allowing for heteroskedasticity of unknown form) are in parentheses. ${ }^{*}, * *$ and $* * *$ indicate statistical significance at the 10 percent level, 5-percent level, and 1-percent level, respectively. 